Review

\title{
Antimicrobial Peptides from Plants
}

\author{
James P. Tam ${ }^{1, *}$, Shujing Wang ${ }^{1,2}$, Ka H. Wong ${ }^{1}$ and Wei Liang Tan ${ }^{1}$
}

1 School of Biological Sciences, Nanyang Technological University, Singapore, Singapore; E-Mails: wangshujing@mail.tsinghua.edu.cn (S.W.); hwka@ntu.edu.sg (K.H.W.); TANW0209@e.ntu.edu.sg (W.L.T.)

2 Department of Pharmacology and Pharmaceutical Sciences, School of Medicine, Tsinghua University, Beijing 100084, China

* Author to whom correspondence should be addressed; E-Mail: jptam@ntu.edu.sg; Tel.: +65-63162863.

Academic Editor: Guangshun Wang

Received: 16 July 2015 / Accepted: 1 September 2015 / Published: 16 November 2015

\begin{abstract}
Plant antimicrobial peptides (AMPs) have evolved differently from AMPs from other life forms. They are generally rich in cysteine residues which form multiple disulfides. In turn, the disulfides cross-braced plant AMPs as cystine-rich peptides to confer them with extraordinary high chemical, thermal and proteolytic stability. The cystine-rich or commonly known as cysteine-rich peptides (CRPs) of plant AMPs are classified into families based on their sequence similarity, cysteine motifs that determine their distinctive disulfide bond patterns and tertiary structure fold. Cystine-rich plant AMP families include thionins, defensins, hevein-like peptides, knottin-type peptides (linear and cyclic), lipid transfer proteins, $\alpha$-hairpinin and snakins family. In addition, there are AMPs which are rich in other amino acids. The ability of plant AMPs to organize into specific families with conserved structural folds that enable sequence variation of non-Cys residues encased in the same scaffold within a particular family to play multiple functions. Furthermore, the ability of plant AMPs to tolerate hypervariable sequences using a conserved scaffold provides diversity to recognize different targets by varying the sequence of the non-cysteine residues. These properties bode well for developing plant AMPs as potential therapeutics and for protection of crops through transgenic methods. This review provides an overview of the major families of plant AMPs, including their structures, functions, and putative mechanisms.
\end{abstract}


Keywords: plant antimicrobial peptides; cysteine-rich peptides; cystine knot; thionin; defensin; hevein; knottin

\section{Introduction}

Higher plants have a broad range of defense mechanisms to counter physical, chemical and biological stress such as drought, cold, heavy metal, pollutants and pathogen attacks from fungi, bacteria and viruses. In response to infection by a variety of pathogens, plants display up-regulation of a set of genes associated with systemic acquired resistance [1]. General resistance is accomplished by the release of secondary metabolites like phytoalexins, tannins and polyphenolic compounds, and the generation of pathogenesis-related (PR) proteins. PR proteins were first discovered in the early 1970s in tobacco leaves in response totobacco mosaic virus infections and were later defined as the induced proteins that are released during pathogenic attacks [2,3]. According to a recent review, there are at least 17 families that have been detected and isolated that possess a wide range of defense-related properties, including antibacterial, antifungal, antiviral, anti-oxidative activity, chitinase and proteinase inhibitory activities [1-4]. This review will focus on peptides which possess antimicrobial activity, namely thionin (PR-13 family), defensin (PR-12 family), hevein-like peptide, knottin, $\alpha$-hairpinin, lipid transfer protein (PR-14 family) and snakin.

Antimicrobial peptides (AMPs) are ubiquitous and found as host defenses against pathogens and pests in diverse organisms ranging from microbes to animals [5]. AMPs exist in different molecular forms, although the majority of them are linear peptides from insects, animals, and plants. Nevertheless, bacteria produce polycyclic peptides such as lantibiotics, and all major forms of life produce circular peptides which include bacteriocins from bacteria, cyclotides from plants and theta-defensins from animals [6-9]. In plants, the majority of AMPs are Cys-rich [10], a feature that enables the formation of multiple disulfide bonds (usually two to six) that contribute to a compact structure and resistance to chemical and proteolytic degradation.

In general, plant AMPs share several common characteristics with those from microbes, insects and animals. They include features such as their molecular forms, positive charge and amphipathic nature, all of which are primarily related to their defensive role(s) as membrane-active antifungals, antibacterials, and antivirals. These features, in addition to being Cys-rich, are well represented by two plant AMP families, thionins and plant defensins. Other families of plant AMPs act on pathogens differently from animal AMPs. For example, hevein-like peptides bind chitins, knottin-type peptides inhibit enzymes such as proteases, and lipid transfer proteins bind lipids to disrupt microbial penetration into cell membranes.

Classification of plant AMP families is largely based on their Cys motifs which exhibit a characteristic Cys pattern with a defined number of non-Cys residues between the two neighboring Cys. Currently, the number of AMPs isolated from a limited number of plants already exceeds a thousand and is likely to increase in the future. Sequence analysis and genomic data mining using these Cys motifs have revealed that Cys-rich peptides (CRPs) with AMP characteristics are under-predicted [11]. 
In model plants, such as rice and Arabidopsis, CRPs may account for about $3 \%$ of the expressed proteins.

Like animal AMPs, AMP expression in plants is constitutive or induced and often tissue-specific. Moreover, plant AMPs are evolvable with hypervariable sequences encased in a particular scaffold characteristic of a given family of AMPs, which is analogous, but to a much lesser extent, to the molecular diversity of vertebrate immunoglobulin-based immunity.

This review aims to provide a general overview of the major families of plant AMPs, including their structures, functions, and putative mechanisms of defense. Additional details on plant AMPs can be found in a number of excellent previous reviews [12-25]. Furthermore, information on AMPs from diverse organisms can be accessed through several databases, such as APD, APD2 [26,27], YADAMP [28], DAMPD [29], and PhytAMP (specific for plant AMPs) [10].

\section{Classification and Characteristics}

Plant AMPs are divided into families based on their sequence similarity, Cys motifs, and distinctive disulfide bond patterns which, in turn, determine their tertiary structure folding. Table 1 lists the major families of plant AMPs based on these criteria; families include thionins, defensins, hevein-like peptides, knottin-type peptides (linear and cyclic), lipid transfer proteins, $\alpha$-hairpinin families, snakins, and unclassified CRP-AMPs. In addition, non-CRP AMPs, which may be rich in other amino acids, are also described in this review, including the Gly-rich peptide (GRP) Pg-AMP1, the Gly- and His-rich peptide shepherins, and peptides of less than 10 amino acids (aa), such as Cn-AMP1 and Cr-ACP1. The following defining features are found in plant AMPs:

1. Mostly characterized as moderate-size (MW of $2-6 \mathrm{kDa}$ ), basic, CRPs with two to six intra-molecular disulfide bonds.

2. Members within a family are classified based on Cys motif, sequence similarity and are conserved in secondary and tertiary structure.

3. One or two additional disulfide bonds are found in members of thionins, defensins, and hevein-like peptides. These additional bonds bolster structural stability without affecting the general scaffold. Because the varying number of Cys residues can create confusion, we refer to AMPs within a family based on the number of Cys when necessary throughout this review (e.g., 6C-thionins contain six Cys and 8C-thionins have eight Cys).

4. In addition to being antimicrobial, AMPs also display "peptide promiscuity", which refers to the multiple functions displayed by a single peptide.

5. All are ribosomally derived and bioprocessed from precursors, which often contain three domains: $\mathrm{N}$ - and C-terminal pro-domains and a mature AMP domain. Mature sequences are often hypervariable and display more variation than the conserved terminal domains in the preproprotein to give sequence diversity for adaptation.

6. Because of cross-bracing by multiple disulfide bonds, most CRP-AMPs with a molecular weight (MW) of 2-6 kDa are structurally compact with high thermal, chemical, and enzymatic stability. 
Table 1. Major families of plant AMPs.

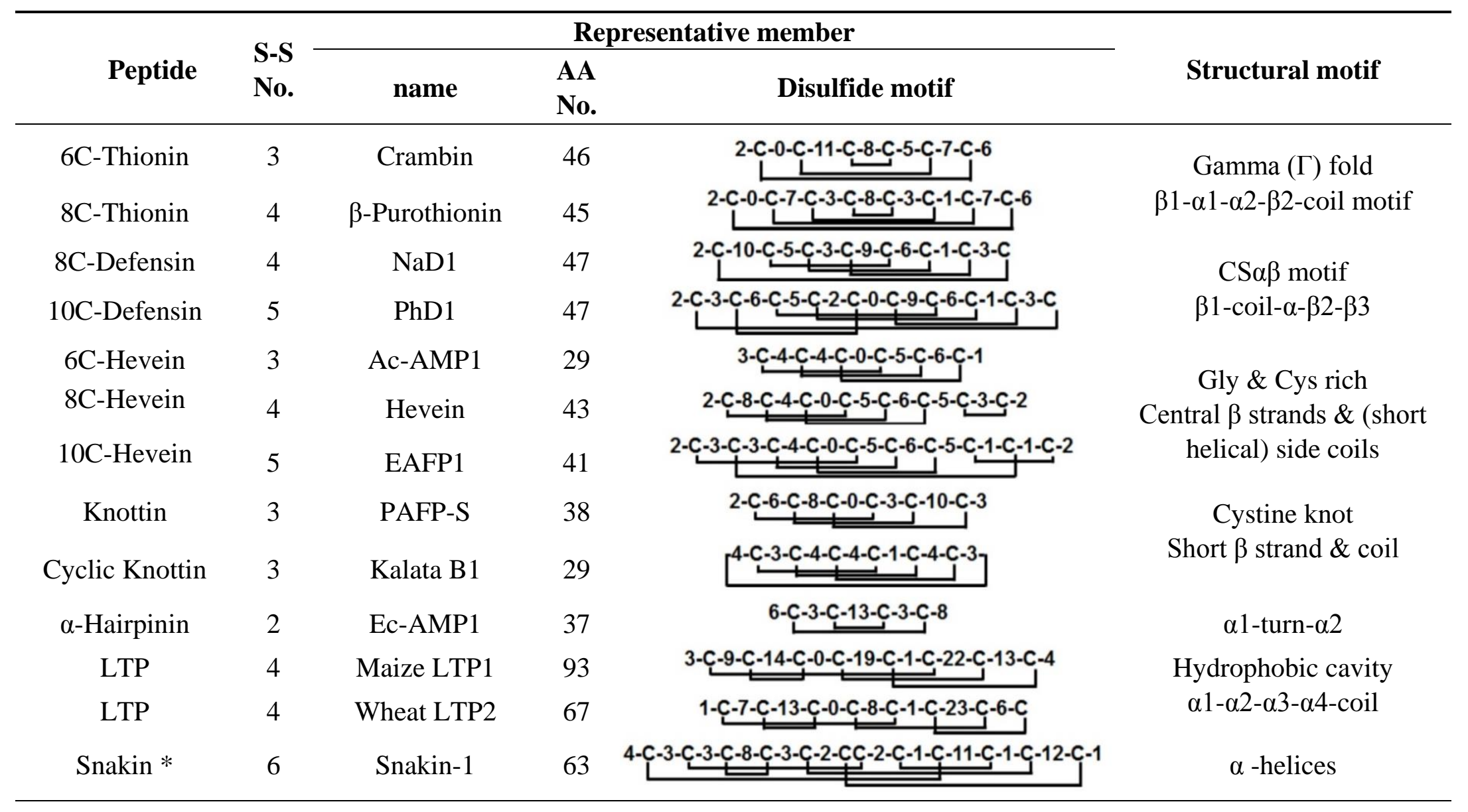

* The disulfide and structural motif of Snakin-1 is predicted based on homology modelling. 


\subsection{Thionins}

$\alpha-/ \beta$-Thionins are the prototypic plant AMP; they are cationic peptides of $45-48$ aa with three or four disulfide bonds [12]. Initially, they were known as plant toxins because of their toxicity towards bacteria [30], fungi [31], plant and animal cells [32], as well as insect larvae [33]. The prototypic thionin with antimicrobial activity, $\alpha$-purothionin, was isolated in the endosperm of wheat [30,34]. Following the discovery of $\alpha$-purothionin, subsequent thionins isolated from other plants are labeled with descending letters of the Greek alphabet in the order of their discovery (e.g., $\alpha$-thionins, $\beta$-thionins, and $\gamma 1 / \gamma 1$-thionins).

Classification of thionins is largely based on $\alpha$-purothionin and includes the $\alpha$-/ $\beta$-thinoins of crambin, viscotoxins, phoratoxin A, hordothionins, and purothinoins. However, $\gamma$-thionins are considered part of the plant defensin family based on structural considerations. Thus, $\alpha-\beta$-thionins share a similar structural fold different from that of $\gamma$-thionins. For convenience, $\alpha / \beta$-thionins with eight Cys residues will be hereafter referred to as 8C-thionins and those with six Cys designated 6C-thionins (Figure 1A,B).
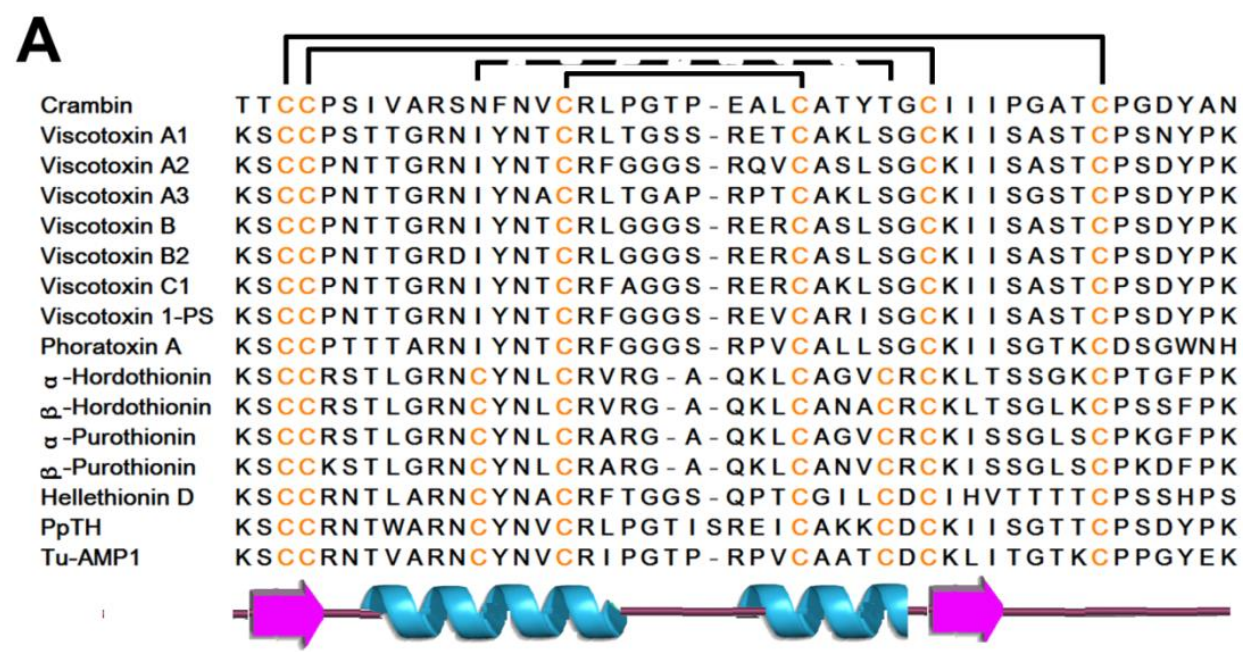

B

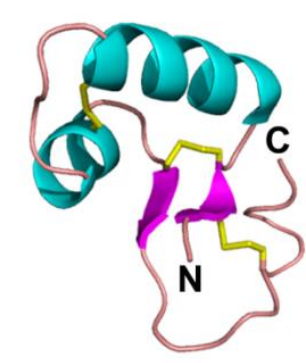

Crambin

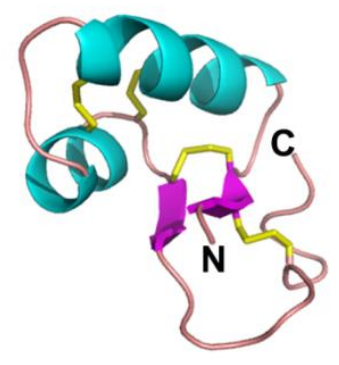

ß-Purothionin

Figure 1. Sequences (A) and structures (B) of representative thionins. The secondary structure is represented by different colors: cyan- $\alpha$ helix; magenta- $\beta$ strand; pink-random coil and yellow-disulfide bonds.

\subsubsection{Occurrences, Distribution, and Biosynthesis}

Thionins have been identified from monocots and dicots and are expressed in different tissues, such as seeds, leaves, and roots [35-37]. The expression of thionins can be induced by infection with various microbes $[38,39]$ and has been shown to be related to the release of the hormone methyl jasmonate upon 
plant wounding or microorganism invasion [38,40,41]. Thionins are ribosomally derived and expressed as preproproteins, wherein the prothionin domain is flanked by two conserved sequences, the $\mathrm{N}$-terminal signaling peptide and C-terminal acidic domain [35,38,42]. Mature thionin sequences display more variation than the conserved terminal domains in the preproprotein due to evolutionary pressure [43]. The three-domain precursor of plant AMPs in CRP families is typical and found in other CRP families, including defensins, hevein-like peptides, and knottin-type peptides.

\subsubsection{Structure}

From the limited number of members identified thus far, thionins have relatively conserved amino acid sequences compared to other plant defense peptides (Figure 1A). They also share a conserved $\beta 1-\alpha 1-\alpha 2-\beta 2$-coil secondary structural motif, which forms a gamma ( $\Gamma)$ fold, a special turn consists of three amino acid residues with the first and third residue connected by a hydrogen bond in the tertiary structure (Figure 1A,B).

Thionins can be loosely classified as pseudocyclics because of an end-to-end disulfide bond linking the $\mathrm{N}$ - and C-termini, conferring a circular structural topology. They are, however, not true pseudocyclics because there are additional non-cysteine amino acids located at both the $\mathrm{N}$ - and C-termini. 8C-Thionins contain four conserved stabilizing disulfide bonds between CysI-CysVIII (Cys numbering in Roman numerals from N-to-C-termini) linking $\beta 1$ to the C-terminal coil, CysII-Cys VII linking the end of $\beta 1$ with the beginning of $\beta 2$, CysIII-CysVI linking $\alpha 1$ and the loop after $\alpha 2$, and CysIV-CysV linking $\alpha 1$ and $\alpha 2$. The $6 \mathrm{C}$-thionins have the same Cys pairing as $8 \mathrm{C}$-thionins except for the absence of the CysII-CysVII disulfide bond. The structure of $8 \mathrm{C}$-thionins, including $\alpha$-/ $\beta$-purothionins, $\alpha$-/ $\beta$-hordothionin, and hellethionin $D$, are similar to that of $6 \mathrm{C}$-thionins with the $\Gamma$-shape but with minor differences in the C-terminal coil region [44-46]. The long arm of the $\Gamma$ fold comprises the $\alpha 1-\alpha 2$ region, and the short arm consists of $\beta 1$ and the $\beta 2$-coil. The large groove between the two arms is proposed to be important for the interaction between thionins and membrane lipids [43]. Most hydrophobic side chains cluster around the outer surface of the long arm, while the hydrophilic chains are located on the surface within the groove or outer face of the short arm (Figure 2A).

\subsubsection{Structure-Function Relationship}

The 6C-thionins with three disulfide bonds include crambin, viscotoxins, and phoratoxin A. Most 6C-thionins are highly basic, amphipathic, and toxic, with the exception of crambin. Crambin is a neutral, hydrophobic, non-toxic peptide identified from Crambe abyssinica with two isomers, P22/L25 and S22/I25 [47,48]. High resolution structures of crambin have been determined by NMR and $\mathrm{X}$-ray/neutron crystallography in both water and detergent [47,49-53]. Viscotoxins (including A1, $\mathrm{A} 2, \mathrm{~A} 3, \mathrm{~B}, \mathrm{~B} 2, \mathrm{C} 1$, and 1-PS) and phoratoxins from the mistletoes share a similar $\Gamma$-shape with $\beta 1-\alpha 1-\alpha 2-\beta 2$-coil motif [54-60].

$8 \mathrm{C}$-Thionins with four disulfide bonds include $\alpha$-/ $\beta$-purothionins, $\alpha$-/ $\beta$-hordothionins, hellethionin-D, Pyrularia Pubera thionin (PpTH), and Tulipa gensneriana bulb-purified AMPs (Tu-AMPs). The monomeric conformation of the 45-aa $\alpha$-hordothionin isolated from barley [61,62] was previously determined by NMR [62], while X-ray crystallography revealed a dimeric structure [61]. A study by Vila-Perello showed that removal of one disulfide bond from $\mathrm{PpTH}$ is sufficient to significantly alter its 
folding [63]. A 45\% size-reduced form of PpTH was synthesized, which only contains residues 7-32 with the two antiparallel $\alpha$-helices stabilized by two disulfide bonds. Size-reduced PpTH appeared to display the same antimicrobial activity and mechanism of action as intact PpTH in selected test microorganisms [64].

A Thionin- $\beta$-purothionin
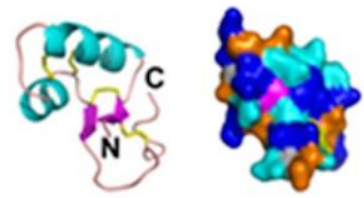

C Hevein-like-Hevein

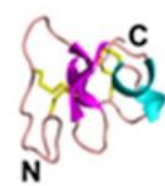

E Linear knottin-PAFP-S

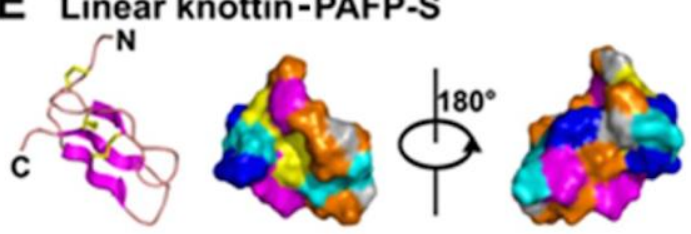

G Lipid tansfer protein 1-Maize LTP1

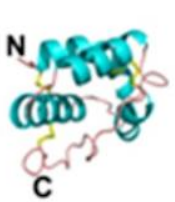

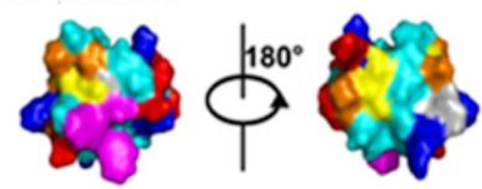
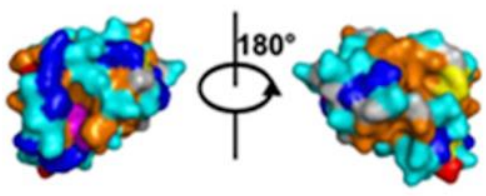
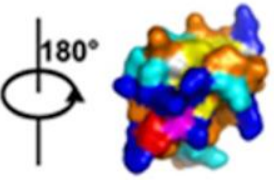

D $\alpha$-hairpinin - EcAMP1

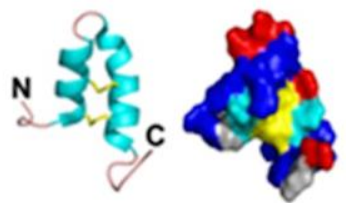

F Cyclic knottin-Kalata B1
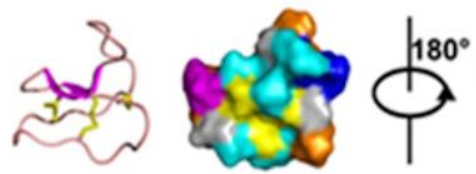

H Lipid transfer protein 2-Wheat LTP2

B Plant defensin-NaD1
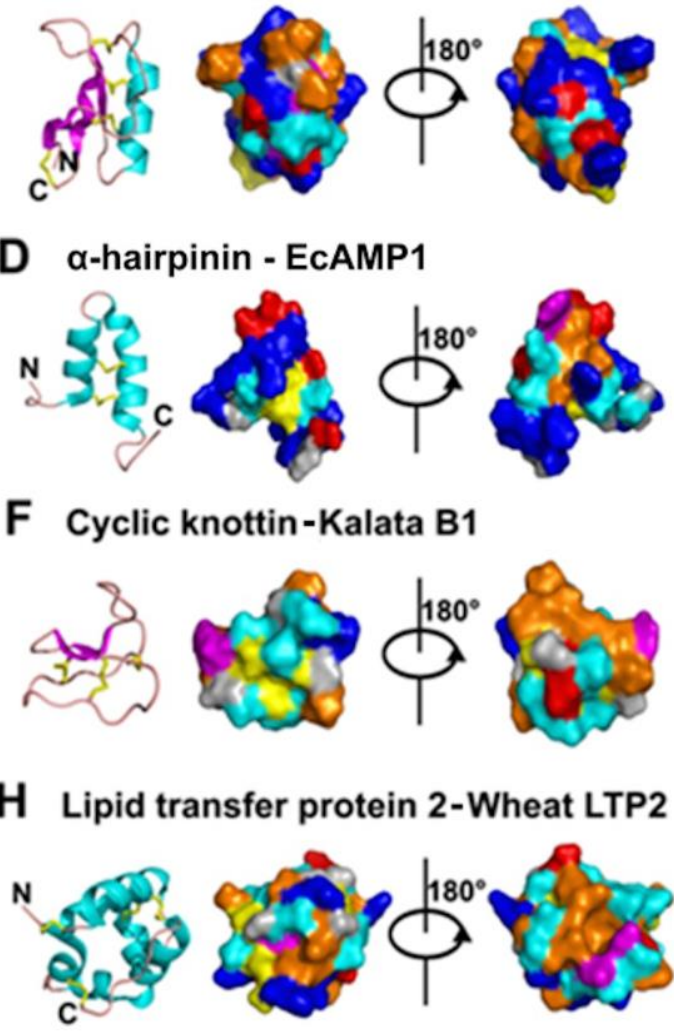

Figure 2. Cartoon illustration and surface plot of representative members of different antimicrobial peptides. The orientation of surface plot (left) of each representative member is the same as the cartoon illustration, while that of the right one is evolved from the left one by $180^{\circ}$ turn around the $\mathrm{y}$ axis. Color representation rules for different amino acids are as follows: blue-positively charged $(\mathrm{R}, \mathrm{K} \& \mathrm{H})$, red-negatively charged ( $\mathrm{D} \& \mathrm{E})$, orange-hydrophobic (I, L, V, A, P \& M), cyan-hydrophilic (S, T, E \& Q), magenta-aromatic $(\mathrm{F}, \mathrm{Y} \& \mathrm{~W})$, yellow-cysteine $(\mathrm{C})$ and gray-glycine $(\mathrm{G})$.

Tu-AMP1 and Tu-AMP2 are antibacterial, antifungal, and can reversibly bind chitin, a key constituent of the cell wall of fungi and exoskeletons of invertebrates, such as insects, anthropods, and nematodes. Initially, they were suggested to be thionin-like peptides, although Tu-AMP2 is a heterodimer of two chains joined by disulfide bonds [65]. However, it is worthwhile to point out that in our review of plant CRPs, the occurrence of heterodimer is exceedingly rare. In our view, it remains to be determined whether the heterodimeric formation occurs during the isolation process.

\subsubsection{Mechanism of Action}

Thionins are hydrophobic and likely elicit their toxicity to bacteria, fungi, and animal and plant cells via membrane interactions with their hydrophobic residues or/and positive surface 
charge $[12,13,18,66-68]$. The proposed mechanism of toxicity is attributed to lysis of cell membranes, but it is still under investigation [30,39,68-70]. Stec proposed a structural model of the thionin-phospholipid interaction to explain the solubilization and lysis of cell membranes [43].

Thionins are known to directly interact with membrane lipids apart from protein receptors $[67,71,72]$. Pyrularia thionin from the nuts of Pyrularia pubera mediates the influx of $\mathrm{Ca}^{2+}$ during certain cellular responses, while Tyr iodination reduces its hemolysis, phospholipase A2 activation, and cytotoxicity [32]. Structure-function studies have demonstrated that Lys1 and Tyr13 in thionins are highly conserved and proposed to be crucial to their toxicity, with the exception of non-toxic, non-lytic crambin. Instead, crambin contains Thr1 and Phe13 residues [32,43,73,74]. Furthermore, Arg10 is suggested to be important to the folding stability of all thionins, as it is an abundant source of hydrogen bonds between $\beta 1, \alpha 1$, and the C-terminal coil [75].

\subsection{Plant Defensins}

Plant defensins are the best known, and likely most abundant, of all plant AMPs with membranolytic functions, according to data mining of selected plant genomes. They are cationic peptides of 45-54 aa with four to five disulfide bonds [76]. Plant defensins have diverse biological functions which include antifungal [77-81], antibacterial [82,83], and $\alpha$-amylase and trypsin inhibitory activity [84,85]. In addition to being antimicrobial, plant defensins are also involved in the biotic stress response, as well as plant growth and development.

Plant defensins were first identified as $\gamma$-thionins, $\gamma 1$-hordothionin, and $\gamma 1$ - $/ \gamma 2$-purothionins from wheat and barley grains $[86,87]$. Thus, they were initially classified as $\gamma$-thionins due to their limited sequence identity (25\%) with $\alpha$-/ $\beta$-thionins. Later, they were found to be unrelated to thionins based on structural features [88]. In 1995, they were grouped as plant defensins based on their sequence, structure, and function similarities with mammalian and insect defensins [76,78,88,89].

\subsubsection{Occurrences, Distribution, and Biosynthesis}

Plant defensins include over 100 members from a wide range of plants, including wheat, barley, tobacco, radish, mustard, turnip, arabidopsis, potato, sorghum, soybean, cowpea, and spinach, among others [15,90]. They have been identified in multiple tissues, tubers [79,91], leaves [79], pods [92], and flowers [93-95], with the majority identified from seeds and roots [96]. Two types of precursors have been identified in plant defensins, wherein the dominant group is composed of the N-terminal signal peptide and a mature plant defensin domain [97], while the minor group is composed of an extra C-terminal acidic pro-domain of 33 aa reportedly associated with the vacuolar sorting mechanism since defensins with this domain were found in vacuoles and those without were found in the outer cell layers $[16,79,95]$.

\subsubsection{Structures}

Plant defensins are generally characterized by four conserved disulfide bonds (except for PhDs, a 10C-plant defensin isolated from Petunia hydrida) with the outer disulfide pair as an end-to-end inner disulfide bridge and the inner three pairs of disulfide bonds forming a cystine knot (see knottins). 
A secondary structure characteristic of plant defensins is a Cys-stabilized $\alpha \beta(\mathrm{CS} \alpha \beta)$ motif of the cysteine knot. The CS $\alpha \beta$ motif was first characterized in charybdotoxin, a $\mathrm{K}^{+}$channel blocker isolated from scorpions [98] and named by Cornet et al. [99]. This motif forms a $\beta 1$-coil- $\alpha-\beta 2-\beta 3$ pattern in the secondary structure, where the $\alpha$-helix is parallel to three antiparallel $\beta$-strands (Figure 3A,B). The $\mathrm{CS} \alpha \beta$ scaffold is stabilized and characterized by: (1) two disulfide bonds between the CXXXC motif from the $\alpha$-helix and the CXC motif in the central $\beta 3$ strand; (2) one disulfide bond between the $\beta 2$ strand and the first loop before the $\alpha$-helix; and (3) an end-to-end disulfide bond between the $\mathrm{N}$ - and C-termini, a disulfide connective similar to thionins. However, plant defensins ( $\gamma$-thionins) differ greatly from $\alpha$ - $\beta$-thinoins in their secondary and tertiary structures. In the secondary structure, $\alpha$-/ $\beta$-thionins show a typical $\beta 1-\alpha 1-\alpha 2-\beta 2$-coil motif, whereas $\gamma$-thionins display a $\beta 1$-coil- $\alpha-\beta 2-\beta 3$ motif. At the tertiary structural level, $\beta 1$ and $\beta 2$ orient antiparallel in $\alpha$-/ $\beta$-thinoins, whereas the corresponding $\beta 1$ and $\beta 3$ in $\gamma$-thionins are oriented in parallel.

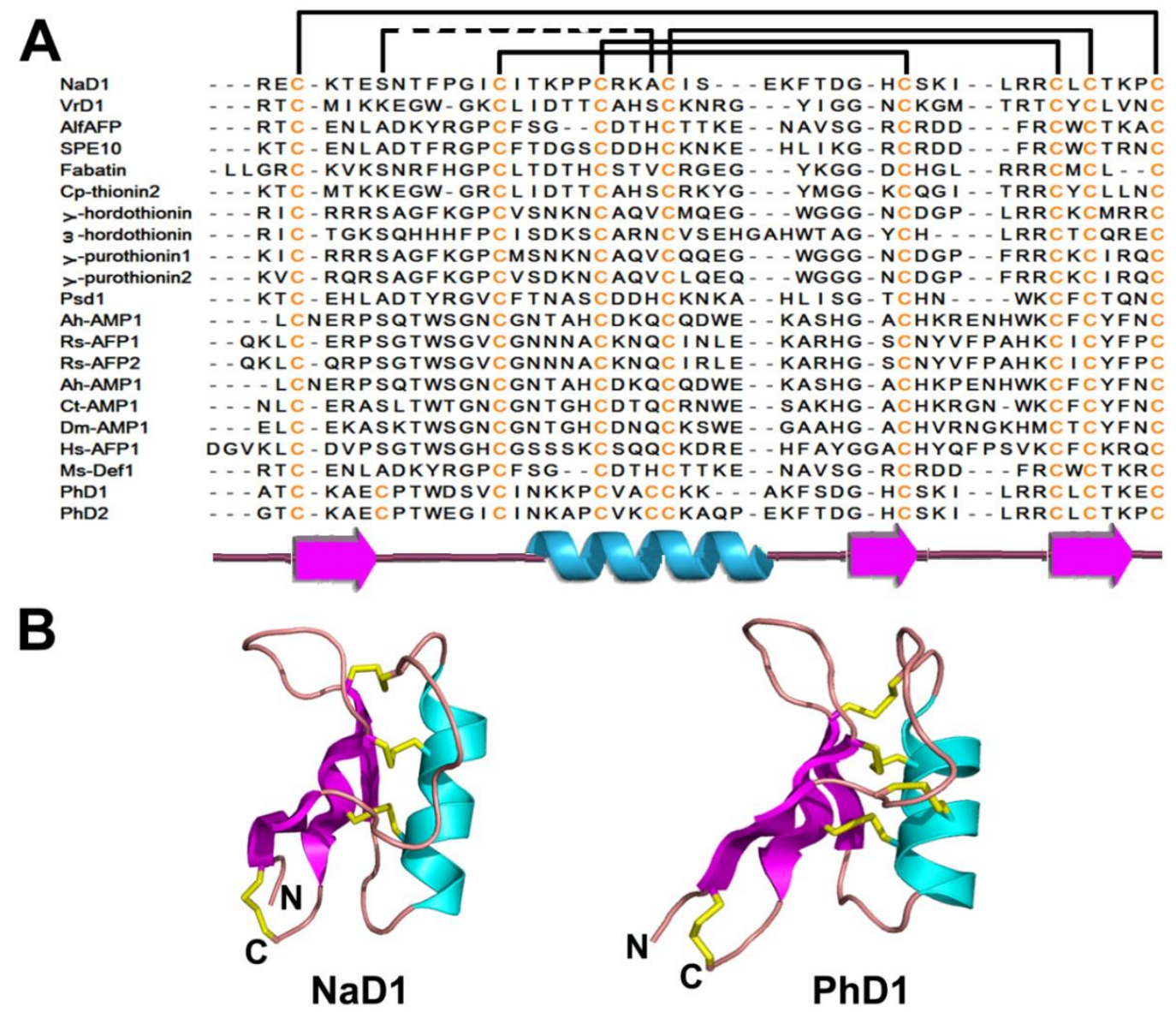

Figure 3. Sequences (A) and structures $(\mathbf{B})$ of representative plant defensins. The secondary structure is represented by different colors: cyan- $\alpha$ helix; magenta- $\beta$ strand; pink-random coil and yellow-disulfide bonds.

Similar to thionins, plant defensins are pseudocyclics (see thionins), with conservation of the disulfide bond between the first and last Cys, conferring a circular structural topology by connecting the side chains of the $\mathrm{N}$ - and $\mathrm{C}$ - termini.

Plant defensins have been reported to be stable in harsh conditions that mimic the digestive system and decoction process, including high temperature $\left(\sim 85^{\circ} \mathrm{C}\right)$, low $\mathrm{pH}(\sim 2.0)$, and oxidative and proteolytic 
environments [100-102]. Although defensins show conservation of the $\operatorname{CS} \alpha \beta$ motif, there are variations in the number of disulfide bonds, primary sequences, and tertiary structures [89,103,104]. It has been shown that Ala substitutions of non-Cys residues on $\mathrm{VrD} 1$ are tolerated in the CS $\alpha \beta$ motif although the structural stability and inhibitory effects vary among the mutants [105].

\subsubsection{Structure-Function Relationship}

Based on the number of Cys, plant defensins are further divided into 8C-plant defensins with four disulfides and 10C-plant defensins with five disulfide bonds.

The 8C-plant defensins include $\mathrm{NaD1}$, VrD1, AlfAFP, $\omega$-hordothionin, Cp-thionin II, Rs-AFPs, Psd1, Fabatins, and Ms-Def1 (Figure 3A,B). NaD1 (47 aa) was identified from the outer cell layers of different flower parts of the ornamental tobacco Nicotiana alata. Its distribution is consistent with its protective roles in reproductive organs. In vitro results showed that $\mathrm{NaD} 1$ inhibits the growth of plant pathogens Botrytis cinerea and Fusarium oxysporus [95,106]. VrD1 (46 aa) from the mung bean Vigna radiata not only inhibits protein synthesis, but is also antimicrobial and insect (bruchids)-resistant [107,108]. $\omega$-Hordothionin (48 aa) purified from barley endosperm inhibits translational activity in both eukaryotic and prokaryotic cell-free systems [109]. The crystal structure of SPE10, identified from Pachyrrhizus erosus seeds [110], shows a dimer with each unit adopting the typical CS $\alpha \beta$ motif [111]. Based on structural analysis and mutation studies, the dimeric conformation of SPE10 was suggested to be associated with its function, while the hydrophobic patch on the molecular head is necessary for its antifungal activity.

AlfAFP from Medicago sativa seeds is an antifungal peptide that provides robust resistance to the fungal pathogen Verticillium dahliae in transgenic potato plants [77,106]. Rs-AFPs (51 aa) purified from Raphanus sativus radish seeds are highly basic oligomeric proteins with an $\mathrm{N}$-terminal pyroglutamic acid. They have a broad antifungal spectrum with an $\mathrm{IC}_{50}=0.3-100 \mu \mathrm{g} / \mathrm{mL}[78,79,81]$. Rs-AFPs are abundant in near-mature and mature seeds and released to create a fungal-suppressing microenvironment after disruption of the seed coat [79]. Ms-Def1 from Medicago sativa seeds strongly inhibits the fungal growth of Fusarium graminearum in vitro [112]; the inhibitory effect is reduced in the presence of $\mathrm{Ca}^{2+}$ ions. Homologous antifungal peptides were also reported from seeds of Aesculus hippocastanum, Clitoria ternatea (Ct-AMP1), Dahlia merckii (Dm-AMP1), Lens culinaris (Lc-def) and Heuchera sanguine (Hs-AFP1) [80,97,113].

Cp-thionin II (47 aa) was identified from Vigna unguiculata cowpea seeds and is antibacterial against both Gram-positive and Gram-negative bacteria such as Staphylococcus aureus, Escherichia coli, and Pseudomonas syringae with minimal inhibitory concentrations of 128,64 , and $42 \mu \mathrm{g} / \mathrm{mL}$, respectively [90]. Psd1, a 46 aa peptide identified from seeds of the pea Pisum sativum, is antibacterial and acts as a $\mathrm{K}^{+}$channel inhibitor based on a surface charge distribution analysis [114]. Fabatins isolated from the broad bean Vicia faba are active against both Gram-positive and Gram-negative bacteria, but inactive against the yeasts Saccharomyces cerevisiae and Candida albicans [115].

PhDs are 10C-plant defensins. From flowers of Petunia hybrids, Lay et al. reported two AMPs with antifungal activity, $\mathrm{PhD} 1$ (47 aa) and $\mathrm{PhD} 2$ (49 aa) [95]. A fifth disulfide bond exists between the $\alpha$-helix and the loop after $\beta 1$ within these defensins that do not alter the typical CS $\alpha \beta$ topology [108]. The fifth disulfide bond appears only to change the corresponding hydrophobic interaction and hydrogen 
bond, as in 8C-plant defensins, to a covalent disulfide bond in $\mathrm{PhD} 1$ without altering the side-chain orientation of substituted residues.

The $\gamma$-thionins which have been reclassified as defensins, $\gamma$-hordothionin and $\omega$-hordothionin from Hordeum vulgare, were shown to inhibit protein translation in rabbit reticulocytes and mouse liver extracts [87]. However, this inhibitory effect was not observed on plants, such as Triticum aestivum, Cucumis sativus, Vicea sativa and H. vulgare, and which may indicate a certain specificity in its mechanism of action. Similarly, no direct interaction was observed between the plant defensins and nucleic acids, which is the proposed mechanism of the inhibitory activity of protein synthesis by the plant thionin family [116]. Instead of protein translation, Mendez et al. suggested that $\omega$-hordothionin may act on protein synthesis at the initiation and elongation step [109].

Defensins isolated from the seeds of Sorghum bicolor, $\mathrm{S} 1 \alpha_{1}, \mathrm{~S} 1 \alpha_{2}$ and $\mathrm{S} 1 \alpha_{3}$, were demonstrated to display inhibitory activity against $\alpha$-amylase activity [84]. They are able to inhibit $\alpha$-amylase obtained from the gut of the insects Periplaneta americana and Locusta migratoria migratorioides, and weakly inhibit the $\alpha$-amylase from human saliva. Defensins from Vigna unguiculata and $\omega$-hordothionin, from $H$. vulgare, also exhibit similar inhibitory activity against insect $\alpha$-amylase [109,117,118], however, no significant inhibitory effect was observed on porcine $\alpha$-amylase by plant defensins [119]. Several plant defensins exhibit the ability to inhibit ion channels. Kushmerick et al. showed that $\gamma 1$-zeathionin and $\gamma 2$-zeathionin from maize kernels block voltage-gated $\mathrm{Na}^{+}$channels reversibly in intact mammalian GH3 cells using the patch-clamp technique [120]. These authors postulated that the ion channel inhibitory effect of defensins may be related to the similar 3D structure with scorpion neurotoxin, a well-known $\mathrm{Na}^{+}$channel blocker. Plant defensins were also shown to inhibit $\mathrm{Ca}^{2+}$ channels [112]. However, no significant inhibitory effect was observed on $\mathrm{K}^{+}$channels by plant defensins [119].

Two homologous peptides that display high sequence similarity to plant defensins were isolated from the plant Cassia fistula, denoted 5459 and 5144 according to their molecular weight [85]. The 5459 defensin was demonstrated to exhibit trypsin inhibitory activity, whereas no inhibitory effect was observed by the 5144 defensin. Another defensin peptide, Cp-thionin from V. uguiculata seeds, was reported to display inhibitory activity against pancreatic bovine trypsin [121].

An enzymatic activity was attributed to a plant defensin. Huang et al. cloned the defensin SPD1 from the roots of Ipomoea batatas and showed that it has the ability to regenerate dehydroascorbate (DHA) to ascorbic acid (AsA) in the presence of glutathione [122]. The peptide is also able to convert monodehydroascrobate (MDA) to AsA in the presence of $\mathrm{NADH}$, functioning as a glutathione-dependent dehydroascorbate reductase. SPD1 is likely to function as a regulator of the redox state of AsA, which has been implicated in the response of the plant cell to reactive oxidative stress [123].

\subsubsection{Mechanism of Action}

The structure-function relationship of plant defensins has been suggested to correlate with their positive charge and amphipathic nature, as illustrated by the structure-surface plot of NaD1 in Figure 2B. Thus, plant defensins could initially bind to microbial membranes through interactions with specific binding sites ("receptors"), as reported for Rs-AFP2, Hs-AFP1, and Dm-AMP1 [16,124,125]. Binding of plant defensins, such as Rs-AFP2 and Dm-AMP1, to the cell membrane results in the influx and efflux of positive ions like $\mathrm{Ca}^{2+}$ and $\mathrm{K}^{+}[126,127]$. Lastly, Ms-Def1 is able to block the $\mathrm{Ca}^{2+}$ channel 
in a manner similar to the $\mathrm{Ca}^{2+}$ channel blocker KP4 [112]. Van der Weerden et al. demonstrated that $\mathrm{NaD} 1$ does not cause membranes permeabilization via a canonical mechanism which involves nonspecific insertion into membranes [128] but rather a cell wall dependent process, likely requiring a specific receptor. The mechanism of the fungicidal action of NaD1 is likely through permeabilization of the hyphae of Fusarium oxysporum, entering into the cytoplasm of the cell and inducing ROS oxidative stress [129]. Hayes et al. reported that the high-osmolarity glycerol (HOG) pathway is involved in the protection of the cell against $\mathrm{NaD} 1$ [130], indicating that the inhibition of the HOG pathway increases the activity of antimicrobial peptides against Candida albicans. Several reviews have discussed in detail the plant defensin mechanism of action [16,101,131,132].

\subsection{Hevein-Like Peptides}

Hevein-like peptides are basic peptides of 29-45 aa with three to five disulfide bonds. They are rich in Gly and contain conserved aromatic residues found in the hevein domain of lectins. Hevein domains bind to chitin [133-135], which is their primary target.

Hevein was first identified as the most abundant protein component from the latex of the rubber tree Hevea brasiliensis and displays strong antifungal activity in vitro [136,137]. It was also reported to be a major allergen from latex involved in human latex-fruit syndrome [138,139]. Similar to hevein, hevein-like peptides inhibit the growth of chitin-containing fungi and defend plants against attack from a wide range of fungal pathogens $[133,140]$.

\subsubsection{Occurrences, Distribution and Biosynthesis}

As a chitin-binding domain, the hevein domain is found in several plant lectins, natural variants of heveins (pseudo-hevein, wheat germ agglutinin, Urtica dioica agglutinin), and AMPs [134,141,142]. Similar to other families of CRP-AMPs, the hevein-like peptide is processed from a three-domain precursor. For example, the cDNA of the Ar-AMP precursor comprises a 25 aa $\mathrm{N}$-terminal signal sequence, 30 aa mature peptide, and 34 aa $\mathrm{C}$-terminal region which is cleaved during post-translational processing [143]. In 10C-hevein (hevein-like peptide containing 10 cysteine residues), there are two different precursor peptide structures in the C-terminal prodomain. The WAMP 10C-hevein from Triticum kiharae have precursor similar to other families CRP-AMPs, with a 45aa C-terminal region [144], while Ee-CBP 10C-hevein from Euonymus europaeus is produced as a chimeric precursor consisting of the mature peptide domain linked to a long C-terminal chitinase-like domain [145]. Andreev et al. [144]also showed that the WAMP-1 and WAMP-2 gene may have originated from ancestral chitinase genes and that a frame-shift deletion of the coding region for the catalytic domain led to the WAMP gene formation.

\subsubsection{Structure}

Hevein-like peptides share conserved Cys, Gly, and several aromatic amino acid residues. They vary substantially in their primary sequences and number of disulfide bonds (from three to five; Figure 4A,B). Thus, hevein-like peptides can be divided into 6C-, 8C-, and 10C-hevein-like peptide subgroups based on the number of Cys they contain. All hevein-like peptides has a cysteine knot motif (see 
knottins). The solid-state and solution structures of the hevein domain, as determined by X-ray crystallography and NMR, respectively [142,146,147], provide the basis for analyzing the carbohydrate binding ability of this domain. Generally, hevein-like peptides contain a coil- $\beta 1-\beta 2$-coil- $\beta 3$ secondary structural motif with variations based on the presence of short turns in the two long coils and $\beta 3$ strand. Antiparallel $\beta$-strands form the central $\beta$-sheet of the hevein motif with the two long coils located on each side stabilized by disulfide bonds.

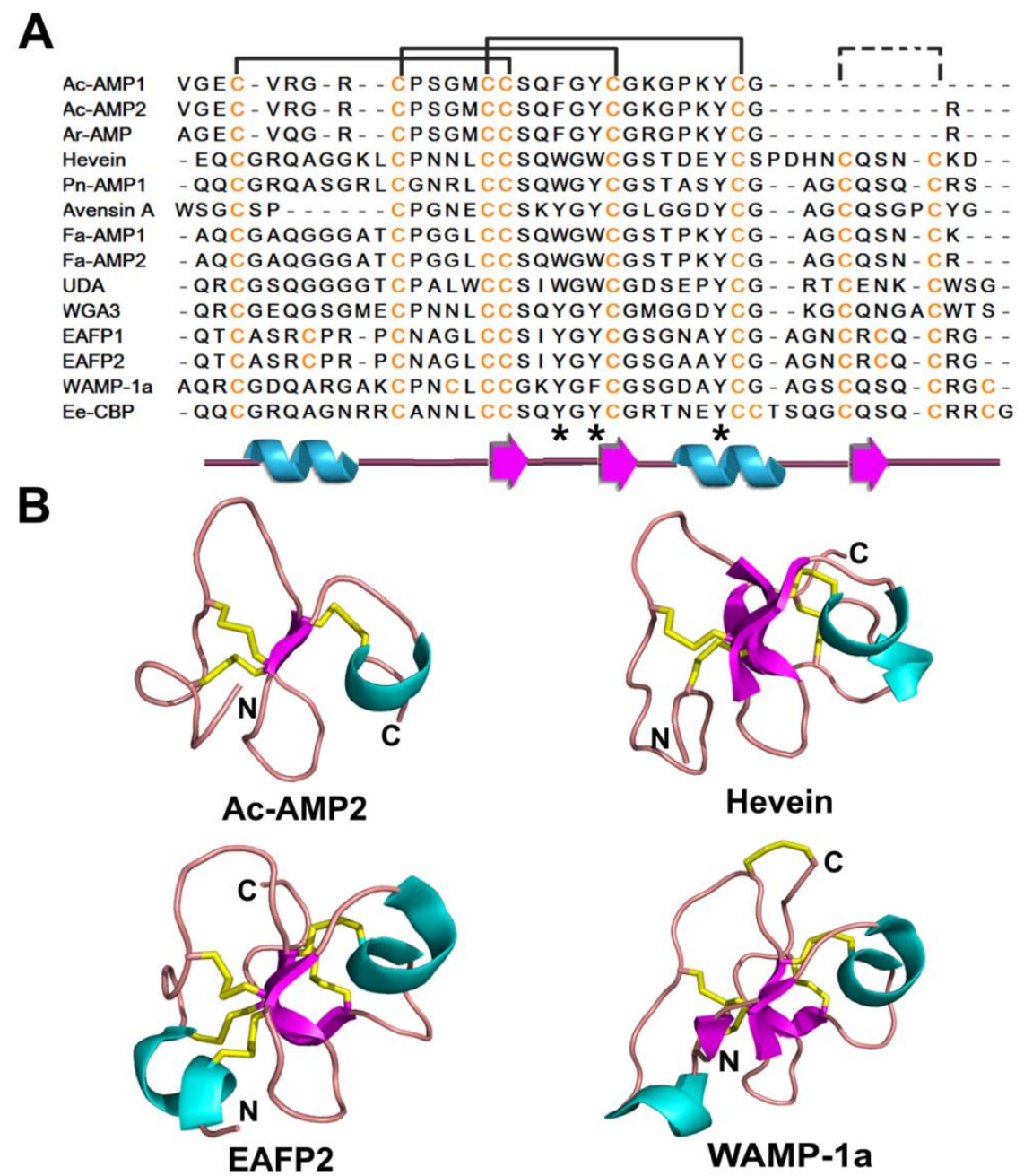

Figure 4. Sequences (A) and structures (B) of representative hevein-like peptides. The secondary structure is represented by different colors: cyan- $\alpha$ helix; magenta- $\beta$ strand; pink-random coil and yellow-disulfide bonds.

\subsubsection{Structure-Function Study}

6C-Hevein-like peptides Ac-AMP1 and Ac-AMP2 isolated from Amaranthus caudatus seeds exhibit antimicrobial activity against both Gram-positive bacteria and plant pathogenic fungi with an IC50 $2-10 \mu \mathrm{g} / \mathrm{mL}$ [148]. Interestingly, their antimicrobial activity is antagonized by cations. Both Ac-AMP1 and Ac-AMP2 are similar to chitin-binding proteins and known to reversibly bind chitin in the C-terminal truncated fold of hevein [149]. This structure consists of a $\beta$-sheet with two antiparallel $\beta$-strands as the main central element, an $\mathrm{N}$-terminal coil region, and $\mathrm{C}$-terminal helical turn. The N-terminal coil region is linked to the two central $\beta$-strands by two disulfide bonds, while the 
C-terminal helical coil is connected to the first $\beta$-strand through a third disulfide bond. Ar-AMP (30 aa) purified from the seeds of amaranth (Amaranthus retroflexus) is another 6C-hevein-like peptide with antifungal activity [143].

Compared to Ac-AMPs, most hevein-like AMPs, including hevein, are 8C-hevein-like peptides with an additional $\mathrm{C}$-terminal sequence containing the fourth disulfide bond. Thus, 8C-hevein contains a central $\beta$-sheet of three antiparallel $\beta$-stands, wherein the last $\beta$-strand is formed from the additional C-terminal sequences and oriented parallel to the fourth disulfide bond. The 6C-hevein32, a truncated form of hevein with the N-terminal 32 aa of hevein similar to Ac-AMP2, is defined as the minimum hevein domain since it presents comparable binding affinity for chito-oligosaccharides as native hevein [150]. Pn-AMP1 and Pn-AMP2 from seeds of the morning glory Pharbitis nil are highly basic (pI 12.02) and thermally stable. They exhibit potent antifungal activity against both chitin-containing and non-chitin-containing fungi with an $\mathrm{IC}_{50} 0.6-75 \mu \mathrm{g} / \mathrm{mL}$, but lose their antifungal activity in acidic ( $\mathrm{pH}$ 2.0) or reducing conditions [151]. As the first hevein-like peptides reported antifungal activity similar to thionins, Pn-AMPs have been successfully cloned into tomato and tobacco plants, endowing these transgenic plants with potent antifungal activities [152,153]. Fa-AMP1 and Fa-AMP2 from seeds of the buckwheat Fagopyrum esculentum, have antifungal and antibacterial activities with an IC50 of 11-36 $\mu \mathrm{g} / \mathrm{mL}$ [82]. Avesin A from seeds of the oat Avena sativa represents another chitin-binding peptide with weak to moderate antifungal properties [154].

Several hevein-like AMPs contain five disulfide bonds (10C-hevein-like peptides), although the location of the fifth disulfide bond varies by peptide. For example, EAFP1 and EAFP2, each 41 aa long, were purified from the bark of the olive Eucommia ulmoides Oliv with an N-terminal pyroglutamic acid [155]. These peptides show inhibitory effects on both chitin-containing and chitin-free fungi with an $\mathrm{IC}_{50} 18-155 \mu \mathrm{g} / \mathrm{mL}$ and can be antagonized by $\mathrm{Ca}^{2+}$. Both solution and crystal structures indicate that EAFPs contain a chitin-binding domain similar to hevein-like peptides with a distinct Cys7-Cys37 fifth disulfide bond bridging the N-terminal coiled region with the third $\beta$-strand [156,157]. In contrast, the fifth disulfide bond within WAMP-1a isolated from the wheat Triticum kiharae connects the C-terminus to the central region of the structure $[158,159]$. Similarly, Ee-CBP from the bark of the spindle tree Euonymus europaeus is a potent antifungal peptide with an $\mathrm{IC}_{50} 1 \mu \mathrm{g} / \mathrm{mL}$ for the fungus Botrytis cinerea [160]. Ee-CBP has a primary sequence similar to other hevein-like peptides but with the fifth disulfide bond at the C-terminus.

\subsubsection{Mechanism of Action}

As a chitin-binding domain, hevein is an excellent model for studying the carbohydrate-peptide interaction, which is reportedly mediated by hydrogen bonding and van der Waals forces. The carbohydrate-induced conformational change to the hevein domain is small based on NMR investigations of pseudo-hevein, a wheat germ agglutinin and truncated hevein mutant $[142,161,162]$. The interaction between the hydrophobic $\mathrm{C}-\mathrm{H}$ groups of carbohydrates and the $\pi$-electron systems of aromatic amino acids (Trp21, Trp23, and Tyr30 in hevein; Figures 3A and 8C) of hevein-like peptides appear to play an important role in chitin binding, as observed in Ac-AMP synthetic mutants, hevein, and a truncated form of hevein (hevein32) at key interacting positions [150,161,163,164]. Studies on 
Pn-AMPs showed that they rapidly penetrate fungal hyphae, leading to hyphal tip bursting, which disrupts the fungal membrane causing leakage of cytoplasmic materials [151].

In addition to the chitin binding function of hevein, Slavokhotova et al. showed an alternative function in which hevein plays a role in the plant defense against fungal infection [165]. WAMPs which contains an additional Ser at position 36 is able to inhibit the proteolytic activity of the secreted fungal protease fungalysin (Fv-cmp), a $\mathrm{Zn}$-metalloproteinase, isolated from Fusarium verticillioides. This protease is able to truncate corn and Arabidopsis class IV chitinases by cleaving within the Gly-Cys site located in the chitin-binding domain of the plant chitinase. The presence of Ser36 prevents WAMP from being digested by Fv-cmp, allowing it to bind to fungalysin, and displace the plant chitinase, thus enabling the chitinase to remain intact and active [165].

\subsection{Knottin-Type Peptides}

Plant knottins belong to a superfamily, with members containing approximately 30 aa. They include inhibitors of $\alpha$-amylase, trypsin and carboxypeptidase families as well as cyclotides. In general, they are among the smallest in size, but most diverse in functions of plant CRP-AMPs. Knottins typically comprise six Cys residues with conserved disulfide bonds between CysI-CysIV, CysII-CysV, and CysIII-CysVI, forming a cystine knot, but their Cys motifs differ among different subfamilies. Both plant defensins and hevein-like peptides also contain a cysteine-knot motif but they differ in their cysteine spacing.

One characteristic of this family is that they display a very broad range of bioactive functions which include hormone-like functions as well as enzyme-inhibitory, cytotoxic, antimicrobial, insecticidal, and anti-HIV activities [166]. Certain cystine-knot (CK) peptides with identical scaffold structures involved in multiple biological functions has been viewed as "peptide promiscuity" [167].

Historically, the knottin-type peptides were discovered as protease inhibitors sharing in common only in a cystine knot motif, and they are named collectively as cystine-knot inhibitor peptides, knottins. The prototypic knottin scaffold was first discovered in the subfamily of potato carboxypeptidase inhibitor (PCI) in 1982 [168]. The use of knottins also distinguishes the CK-CRPs from those initially described in the structures of the protein growth factors found in animals [169]. As a superfamily, they are believed to be the largest group of plant peptides associated with AMPs, surpassing defensins in the number of molecular forms and sequence diversity.

Knottins in the cyclotide and trypsin inhibitor families are found in two molecular forms, cyclic and linear, based on the presence or absence of backbone (head-to-tail) cyclization. In literature, cyclic knottins of the squash trypsin subfamily are often included in the cyclotide subfamily. Apart from their Cys residues, cyclic knottins and cyclotides share little sequence identity. Currently, both linear (acyclotides) and cyclic (cyclotides) forms of the cyclotide subfamily are found in plants.

\subsubsection{Occurrences, Distribution, and Biosynthesis}

Linear knottins are found not only in plants, but also in other biological sources, including fungi, insects, and spiders. Thus, CK peptides with identical or related scaffold structures found in diverse life forms provide an example of parallel evolution of protein structures. Cyclotides and their acyclic variants are found only in plants, from the dicot plants of the Rubiaceae, Violaceae, Cucurbitaceae, 
Fabaceae, and Solanaceae families to a monocot plant of the Poaceae family, with predicted wide and abundant distribution [170-177].

Cyclotides and certain members of cyclic knottins of the squash family are produced from precursor proteins encoding one or more cyclotide domains. The precursor is composed of an endoplasmic reticulum signal region, pro-domain, one (or more) mature cyclotide domain(s), and a short C-terminal tail [172]. However, there are variations in their biosynthesis. A recent report on cyclotides such as cliotides (cT1-cT12) identified from Clitoria ternatea showed that they originate from chimeric precursors consisting of Albumin-1 chain A and cyclotide domains [173]. Studies have shown that an asparaginyl endoproteinase could be involved in the backbone cyclization of cyclotides [178-181]. Our laboratory has isolated one of the bioprocessing enzymes responsible for the backbone cyclization process from C. ternatea, butelase 1 [181]. Butelase 1 acts as a transamidase, cyclase and ligase and is C-terminal specific to produce Asx-Xaa bonds, with Xaa being a diverse group of residues. Butelase 1 cyclizes various peptides of plant and animal origin efficiently and is the fastest peptide ligase known. Linear variants of cyclotides share high sequence identity and contain a similar knottin scaffold but are biosynthetically unable to cyclize from their precursors [173,182]. Violacin A, a naturally occurring linear cyclotide from Viola odorata, lacks the essential bioprocessing signal, the C-terminal Asn residue required for cyclization due to the presence of a stop codon earlier in the C-terminal sequence [177].

Cystine knot $\alpha$-amylase inhibitors (CKAIs) are plant-derived $\alpha$-amylase inhibitors originally isolated from Amaranthus hypocondriacus [183]. They are the smallest family of proteinacous $\alpha$-amylase inhibitors among the seven known families [184]. Unlike other knottins, these peptides are rich in proline residues, with at least one of them existing in a cis-configuration [185]. In recent studies, Nguyen et al. have isolated an additional three members of CKAIs from the leaves and flowers of Wrightia religiosa [186] and another five members from the leaves of Allamanda cathartica [187]. These CKAIs contain 30 residues, two residues shorter than AAI, and share high sequence homology to each other.

\subsubsection{Structure}

A common knottin structural motif was initially defined in 1994 as a CK and triple-stranded $\beta$-sheet with a long loop connecting the first and second $\beta$-strand [166]. The first two disulfide bonds (between CysI-CysIV and CysII-CysV), together with their connecting backbone, form an embedded ring that is penetrated by the third disulfide bond (between CysIII-CysVI). Studies on the subfamily of squash trypsin inhibitors and PCIs showed that only two disulfide bonds (between CysII-CysV and CysIII-CysVI) in the knottin scaffold are highly conserved and sufficient to maintain the Cys-stabilized $\beta$-sheet motif $[188,189]$. It is worthwhile to point out that cystine-knot motifs appear to be common occurrence in plant CRP-AMPs. They are found, at the primary structure level, in plant defensins and heveins. However, they differ in the secondary and tertiary structure levels.

Despite the common knottin motif, knottin-type peptides have hypervariable sequences, differing by their amino acid sequences, the length between CysIII-CysIV and CysIV-CysV, and the linear and cyclic nature of the peptide backbone (Figures 4 and 5). Owing to the high sequence tolerance of the knottin scaffold and its diverse biological functions, the knottin scaffold has been used as a template for drug design. Knottins engineered by substitution of individual or several consecutive amino acids and/or 
insertion of additional amino acids without changing the structural integrity have been shown to provide novel bioactivity or increase stability [190].

Plant knottin-type peptides, particularly the subfamily of cyclotides, have been reported to possess high thermal, chemical, and enzymatic stability [186,191,192]. Cyclotides are also resistant to gastrointestinal proteases like trypsin, chymotrypsin, pepsin, or elastase [191,193], and certain members of cyclotide family can even penetrate the intestinal mucosa excised from rats [194,195]. Disulfide bonds in the knottin scaffold are crucial to its chemical and enzymatic stability based on studies of various members of cyclotides such as violacin A, kalata B1, and kalata B2 [177,191], whereas the cyclized backbone is important for exopeptidase resistance. For example, stability tests show that acyclic vilacin $\mathrm{A}$ is resistant to endopeptidase, trypsin, and thermolysin, comparable to cyclotides. The exoprotease aminopeptidase $\mathrm{M}$ cleaves the first two $\mathrm{N}$-terminal residues of violacin A but leaves the third and fourth residues intact due to their proximity to the disulfide bond. Although no large differences are observed in the structure and flexibility between cyclotides and their corresponding linear analogs under standard conditions, simulation studies of linear and circular squash inhibitors revealed that cyclization increases resistance to high temperatures by limiting structure unfolding [192].

CKAIs exhibit another method in which these peptides are able to maintain stability against exopeptidases without a cyclic backbone structure, a pseudocyclic structure [186]. In wrightides, CKAIs isolated from the plant $W$. religiosa, the N-terminus and C-terminus are protected by the formation of disulfide bonds at the ultimate or penultimate residues. Structural analysis showed that this arrangement allows the termini to loop back to the peptide chain via the disulfide bonds especially at the N-terminal, forming a pseudocyclic structure. Allotides, CKAIs from A. cathartica, and AAI also exhibit similar structural features $[183,187]$.

\subsubsection{Structure-Function Relationship}

With the exception of the cyclotide subfamily, the majority of knottins, are linear. They include the subfamilies of PAFP-S, Mj-AMPs, insect $\alpha$-amylase inhibitor, squash trypsin inhibitor CMTI-1 and carboxypeptidase A inhibitor, as well as several linear homology analogs of cyclotides (violacin A and panitide L2; Figure 5A,B). Several knottin-type peptides were identified as plant AMPs, such as PAFP-S, Mj-AMPs, and Psacotheasin (Ps). PAFP-S was identified from seeds of Phytolacca americana and models the typical knottin structure of antifungal peptides [196]. Mj-AMP1 and Mj-AMP2 extracted from Mirabilis jalapa seeds have a broad spectrum of antimicrobial activity, being active against all 13 tested fungal pathogens and two tested Gram-positive bacteria but inactive against Gram-negative bacteria and cultured human cells. Reduced and non-reduced SDS-PAGE results suggest that Mj-AMP1 and Mj-AMP2 exist as dimers in their native form [197]. Ps from Psacothea hilaris is a 34 aa antibacterial peptide with a minimal inhibitory concentration of 12.5-25 $\mu \mathrm{M}$ [198].

Knottin-type peptides act as $\alpha$-amylase or protease (carboxypeptidase A or trypsin) inhibitors (Figure 5A,B) and propagate plant defense mechanisms by conferring resistance to insects, pests, and pathogens [199]. The $\alpha$-amylase inhibitor identified from A. cathartica and W. religiosa are the smallest peptide inhibitor of $\alpha$-amylase activity (30 aa) [186,187]. Wr-AI1 and Wr-AI2, CKAIs from the plant W. religiosa, have been demonstrated to inhibit the $\alpha$-amylase activity isolated from Tenebrio molitor (yellow mealworm), but no inhibitory was observed in fungal or mammalian $\alpha$-amylase. Similar 
$\alpha$-amylase inhibitory activity was observed from allotide Ac4. However, it was found that allotides interact with TMA differently from AAI and wrightides due to variation in the $\mathrm{N}$-terminal sequences and high content of $c$ is-proline. AAI confers pest resistance to plants by targeting insect $\alpha$-amylase, but does not interfere with $\alpha$-amylase from mammalian digestive systems, suggesting that amaranth seed AAI could be an attractive candidate to endow pest resistance to transgenic plants.

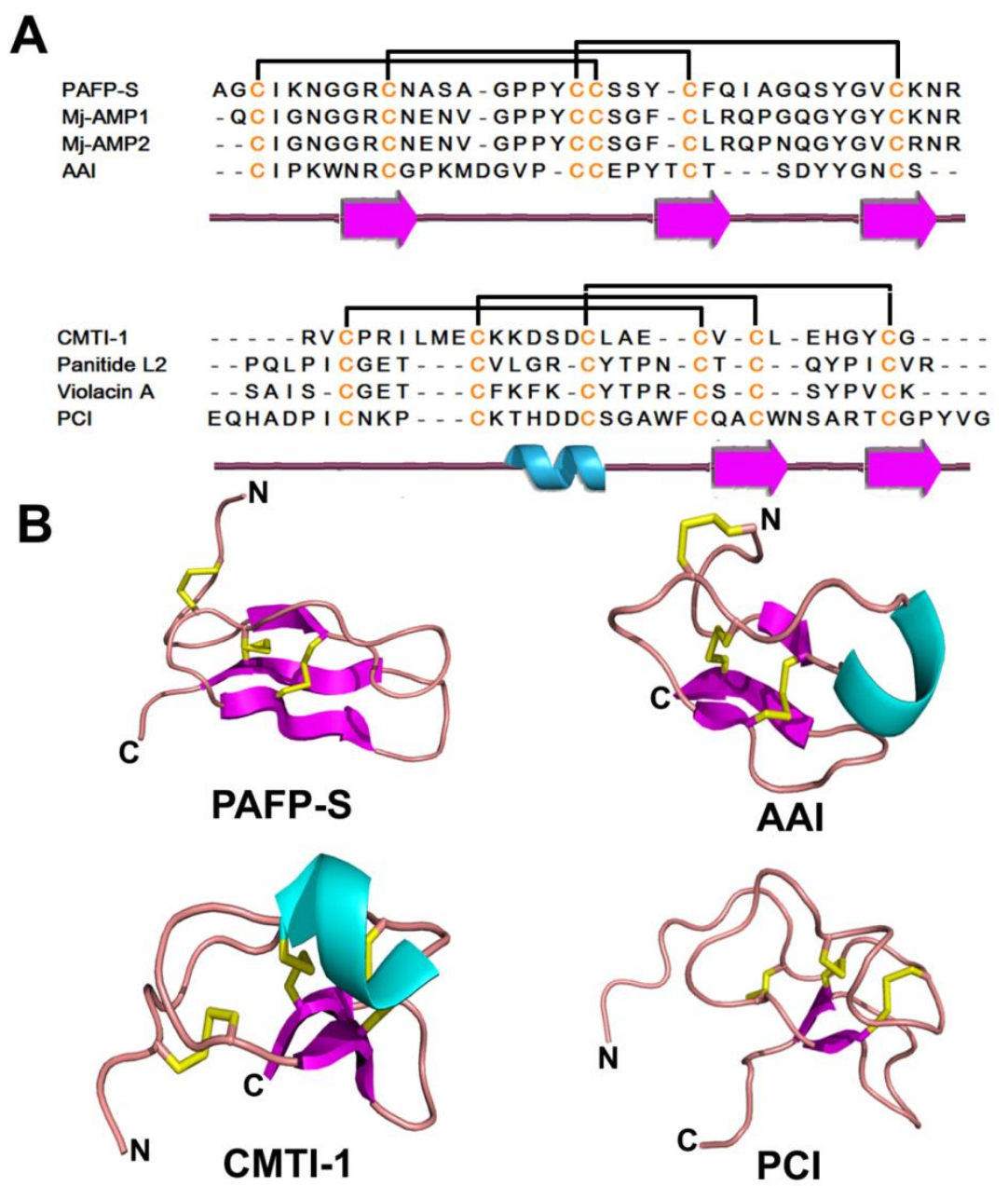

Figure 5. Sequences (A) and structures (B) of representative linear knottin-type peptides. The secondary structure is represented by different colors: cyan- $\alpha$ helix; magenta- $\beta$ strand; pink-random coil and yellow-disulfide bonds.

Squash trypsin inhibitors are 27-32 aa knottin-type peptides (e.g., CMTI-II of both pumpkin Cucurbita maxima and fig leaf gourd Cucurbita ficifolia seeds) [200]. The first squash inhibitor containing the knottin scaffold was reported from the seeds from squash of the Cucurbitaceae family [201]. Most squash trypsin inhibitors have linear backbones, except for MCoTI-I and MCoTI-II. However, not all the protease inhibitor peptides are knottin-type, such as sun flower trypsin inhibitor, a 14 aa cyclic peptide braced by a central disulfide bond [202]. Another type of knottin with protease inhibitory function includes carboxypeptidase inhibitors from potatoes [145] and tomatoes [203]. Potato carboxypeptidase inhibitor (PCI) (39 aa) has long loops instead of the typical $\beta$-strands observed in other knottin-type peptides. It binds the active site of carboxypeptidase A with the C-terminal tail as 
an active fragment binding to protease in a stopper-like manner and uses some aromatic residues as secondary binding sites [204,205].

A few linear variants of cyclotides have also been identified from the monocot rice plant Panicum laxum of the Poaceae family as Panitide L1-12 [175]. Several Panitides are active against Escherichia coli and cytotoxic to HeLa cells. The other subgroup of knottin-type peptides is cyclotides, including typical cyclotides and cyclic knotttins such as MCoTIs (Figure 6A,B). Cyclotides are 29-37 aa in length with a CK arrangement of three disulfide bonds which are widely involved in plant defense, as deduced from their activity against insects, nematodes, and mollusks [206-208]. The first cyclotide was identified in 1973 as an uterotonic agent from the African plant Oldenlandia affinis, a main component of medicinal tea used to accelerate childbirth [209]. Cyclotides have potential pharmacological functions, considering their antimicrobial, anti-HIV, anti-tumor, and neurotensin activities [22]. Cyclotides are found mainly in Rubiaceae (coffee), Violaceae (violet) and families. They are highly variable in sequence, but conserved in structure, and are divided into two types: Möbius and bracelet. Möbius types contain one cis-Pro in loop 5 and a twist in the cyclic backbone, while the bracelet type does not [210]. Yet, both types do not significantly differ from one another in the general scaffold structure.

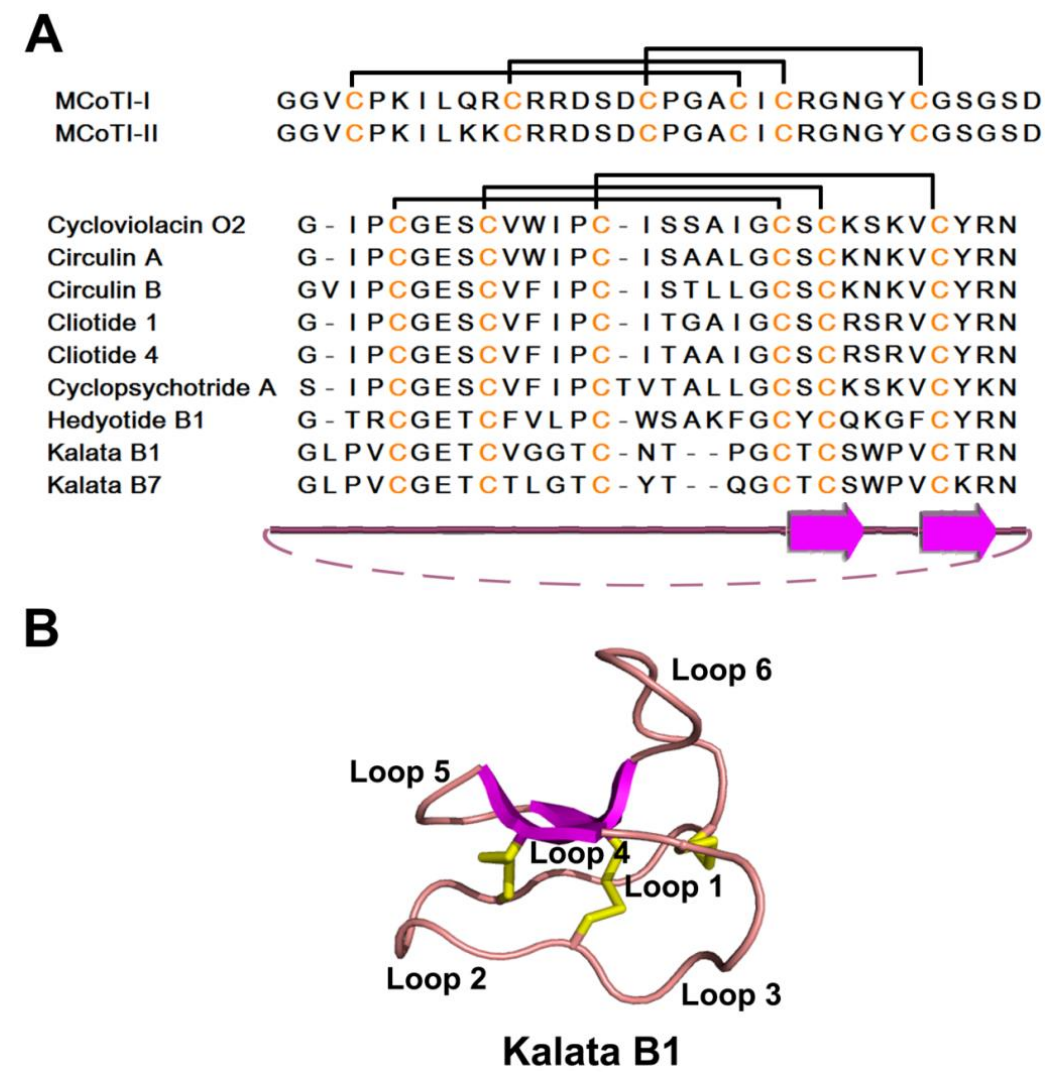

Figure 6. Sequences (A) and structures (B) of representative cyclic knottin-type peptides. The secondary structure is represented by different colors: magenta- $\beta$ strand; pink-random coil and yellow-disulfide bonds.

Antimicrobial activity of cyclotides was first reported for four synthetically produced cyclotides isolated from coffee plants, kalata B1, circulin A, circulin B, and cyclopsychotride [211]. 
Subsequently, more cyclotides were reported to have antimicrobial activity. Cyclotides kalata B1 and B7 (29 aa each) from the tropical plant Oldenlandia affinis display antibiotic effects both in salt and salt-free medium [212]. While the 30 aa cycloviolacin $\mathrm{O} 2$ from Viola odorata is resistant to Gram-negative bacteria [213], cliotides cT1 and cT4 from Clitoria ternatea show antimicrobial activity against Gram-negative bacteria and cytotoxicity to HeLa cells [173]. Hedyotide B1, on the other hand, is a positively charged bracelet cyclotide from Hedyotis biflora, rich in aromatic residues and active against both Gram-positive and Gram-negative bacteria [214].

MCoTI-I and MCoTI-II are two squash trypsin inhibitors from Momordica cochinchinensis that contain a cyclized backbone [215] and have large sequences differences from typical cyclotides, as discussed above (Figure 6A). The $\mathrm{C}$ - to N-cyclization in MCoTI-II has no significant impact on the protein structure, though cyclized squash inhibitors are postulated to be less sensitive to exopeptidases [216]. Based on structural studies of MCoTI-II in free and complex forms, Heitz revealed that the cyclization and active site loops of MCoTI-II are flexible in solution, but converge into a single, well-defined conformation upon binding trypsin [217]. Compared to previously defined cyclotides, such as kalata B1 or circulin A, MCoTI-I and MCoTI-II share similar motifs wherein two disulfide bonds stabilize the $\beta$-sheet but differ greatly in their amino acid sequences and in loops 3 and 6 [217]. Furthermore, MCoTIs have an entirely charged surface versus the amphipathic nature of circulin A. These differences may explain functional disparities such as squash inhibitor MCoTIs having no antibacterial activity, unlike circulins and kalata B1.

\subsubsection{Mechanism of Action}

Generally, knottin-type peptides with membranolytic functions are amphipathic in nature like other AMPs, a characteristic necessary for membrane interactions which implement their antimicrobial effects. For example, the surface plots of PAFP-S and kalata B1 show hydrophobic patches surrounded by several hydrophilic residues (Figure 2E,F). However, in contrast the strongly cationic-charged thionins and plant defensins, most cyclotides are unlikely to have a strong electrostatic interaction with membranes since they are normally weakly positive or neutral at physiological pH (Figure 2F) [218]. The interaction of cyclotides with membranes has been previously investigated in vitro using the detergent dodecylphosphocholine [219]. In this study, the structure of kalata B1 was not significantly altered upon binding the detergent; binding was largely mediated by the strong hydrophobic interactions between cyclotide loops and lipid tails of the detergent, as well as favored by the weak interactions between positively charged kalata B1 and the polar head of the detergent However, similar studies on kalata B2 and cycloviolacin O2 suggest that different cyclotides have different membrane binding modalities because of the varied location of hydrophobic patches in cyclotides [220].

\subsubsection{Knottin Scaffold in Pharmaceutical Engineering}

The knottin scaffold is an excellent candidate for peptide-based pharmaceutical engineering [221] as a result of several features: (1) remarkable proteolytic, thermal, and chemical stability due to the CK and backbone cyclization of cyclotides; (2) feasibility of chemical synthesis due to small size; and (3) excellent sequence tolerance due to sequence variation in loop regions. 
Synthesis of cyclotides and cyclic knottins. To exploit cyclotides and cyclic knottins for agricultural and medical use, it is necessary to develop efficient methods for their production. Methods employed to date include solid phase peptide synthesis [9,211,222-227], as well as chemo-enzymatic and biological methods using modified inteins [210-213] and Asn-endoprotease such as butelase-1 [228-231].

Irrespective of the means of its preparation, a linear precursor containing a macrocycle sequence is first generated, followed by a macrocyclizaion step to give a head-to-tail backbone-cyclized compound. The head-to-tail cyclization poses a substantial hurdle and challenge because it is highly entropy-disfavored due to the great distance between the $\mathrm{N}$ - and C-termini, but has been solved elegantly by the discovery of the thia zip cyclization reaction in 1997 [232]. Thia zip cyclization is an entropic reaction, characterized by a series of entropic ring expansion by making use of the multiple Cys residues in a CRP-linear precursor functionalized with an $\mathrm{N}$-terminal Cys and a C-terminal thioester. This construct enables a thiol-thioester to form a thiolactone and then thiol-thiolactone exchange reactions in tandem, ending with a head-to-tail thiolactone which spontaneously forms a peptide bond through an S, N-acyl shift. In 1997, the first report on both Möbius and bracelet cyclotides have been synthesized by the thia zip reaction and regio-selective disulfide bond formation to guarantee the correct knottin scaffold [225]. Since then, many successful syntheses of cyclic CRPs based on thia zip cyclization have been reported. We have recently reviewed the progress of macrocyclization relevant to cyclotides and cyclic knottins [9]. Since 2012, new advances based on amide-to-amide transpeptidation reaction have made preparation of cyclotides, cyclic knottins and other macrocycles possible through chemical or biological means [181].

\section{5. $\alpha$-Hairpinin Family}

The $\alpha$-hairpinin family is composed of Lys/Arg-rich plant defense peptides. $\alpha$-Hairpinin AMPs share a characteristic C1XXXC2-(X)n-C3XXXC4 motif in their primary sequence and, more importantly, a helix-loop-helix secondary structure (Figure 7A,B). The helix-loop-helix or $\alpha 1$-turn- $\alpha 2$ motif has both $\alpha$-helices oriented antiparallel and is stabilized by two disulfide bonds in the tertiary structure. This structure is a surprise finding in plant CRPs, and the $\alpha$-hairpinin family is structurally distinguished from the $\beta$-strand decorated CRP-AMPs, such as thionins, defensins, and knottin-type peptides.

Thus far, only a limited number of $\alpha$-hairpinin AMPs have been reported, including MBP-1, MiAMP2s, Ec-AMP1, Luffin P1, VhT1, BWI-2c, Tk-AMP-Xs, and Sm-AMP-X. MBP-1, a 33 aa peptide isolated from the maize kernel, inhibits spore germination and hyphal enlongation of several plant pathogenic fungi and bacteria in vitro [233]. MiAMP2 peptides (50 aa) isolated from the nut kernel of Macadamia integrifolia inhibit various plant pathogenic fungi in vitro [234]. They are produced from a 666 aa precursor protein homologous to vicilin 7S globulin. Ec-AMP1 from the seeds of the baryard grass Echinochloa crus-gali was reported to have antifungal activity against several phytopathogenic fungi with an $\mathrm{IC}_{50}=1-10 \mu \mathrm{M}$. A confocal microscopy study showed that Ec-AMP1 binds the fungal conidia surface and then internalizes and accumulates in the cytoplasm without disturbing membrane integrity [235].

Tk-AMP-X1 and Tk-AMP-X2 extracted from the wheat Triticum kiharae and Sm-AMP-X from seeds of the chickweed Stellaria media are another two $\alpha$-hairpinin members with antifungal activity [236,237]. Both are produced from multimodular precursor proteins. The Tk-AMP-X-related 
sequences have been shown to be widespread in crops such as barley, rice, and maize, which suggest the importance of this type of plant defense peptide. VhT1 from the seeds of Veronica hederifolia and BWI-2c from seeds of the buckwheat Fagopyrum esculentum represent a new family of trypsin inhibitors with an $\alpha$-hairpinin structure and act as defensive peptides in plants [238,239]. Luffin P1, extracted from the seeds of the sponge gourd Luffa cylindrical, has been shown to have anti-HIV-1 activity in HIV-1-infected C8166 T-cell lines in vitro [240]. This study proposed that Luffin P1 displays a novel inhibitory mechanism owing to its charge complementation with viral and cellular proteins.

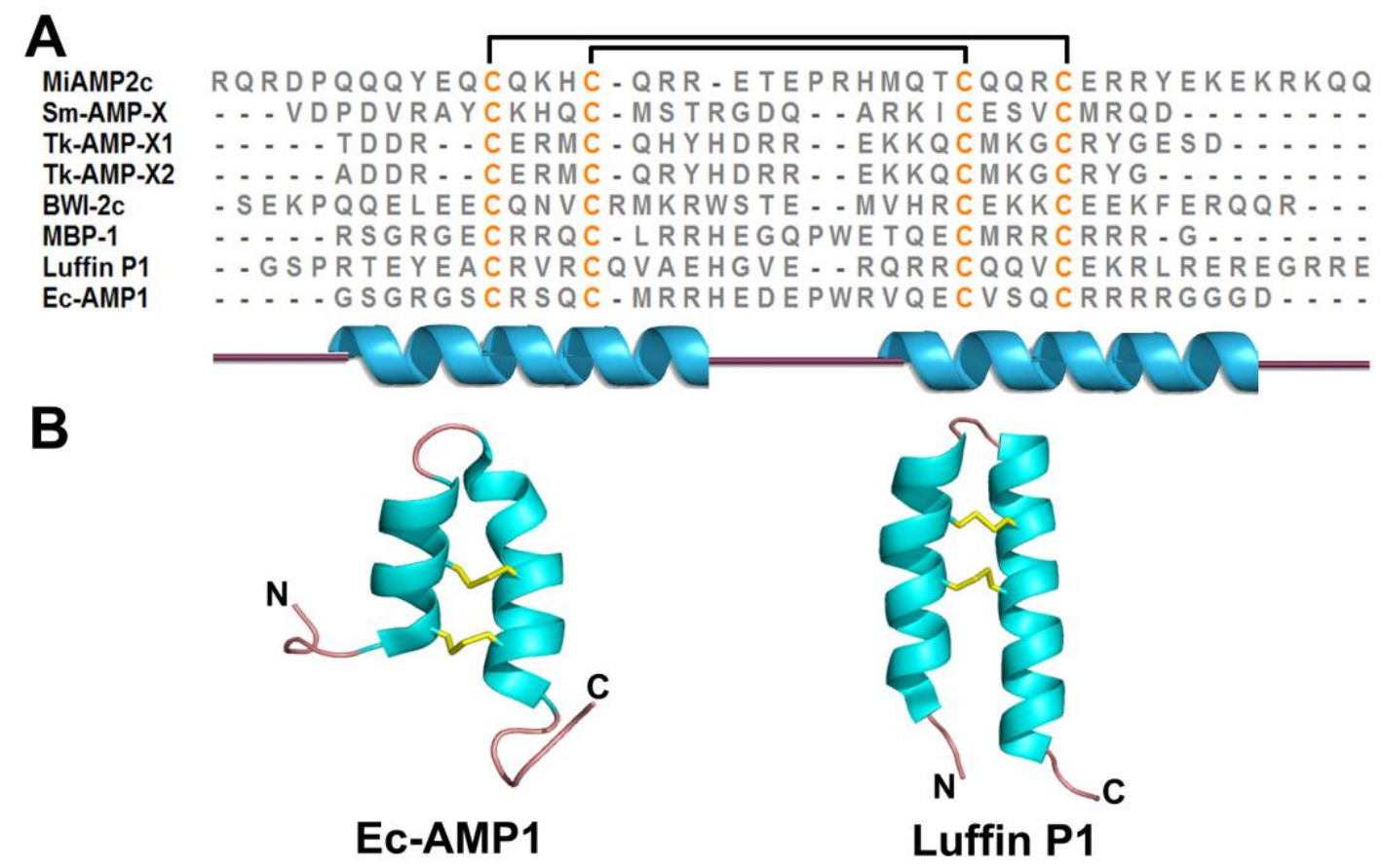

Figure 7. Sequences (A) and structures (B) of representative $\alpha$-hairpinins. The secondary structure is represented by different colors: cyan- $\alpha$ helix; pink-random coil and yellow-disulfide bonds.

\subsection{Lipid Transfer Proteins}

Plant lipid transfer proteins (LTPs) and snakins (described in the following section) are two families of CRP-AMPs with MW $>7 \mathrm{kDa}$, and are considered proteins. LTPs are cationic proteins of approximately 70 and 90 aa with eight Cys residues. They are distinguished from other CRP-AMPs by their lipid transfer activity, in which they bind a wide range of lipids including fatty acids (C10-C14), phospholipids, prostaglandin B2, lyso-derivatives, and acyl-coenzyme A. Consequently, they are also called non-specific LTPs [4,241,242]. LTPs can inhibit growth of fungus and some bacterial pathogens and are involved in the plant defense system. LTPs are subdivided into LTP1s (MW $=9 \mathrm{kDa}$ ) and LTP2s (MW $=7 \mathrm{kDa}$ ) based on their molecular mass.

\subsubsection{Occurrences, Distribution, and Biosynthesis}

Plant LTPs have been identified in various species, such as seeds of the radish, barley, maize, Arabidopsis, spinach, grapevine, wheat, and onion [4,241-246]. They are synthesized as precursors containing a signal peptide of 20-25 aa and a mature protein with eight Cys [247]. 


\subsubsection{Structure}

Although LTPs vary in their primary sequence, they share a defining structural feature, a conserved inner hydrophobic cavity surrounded by $\alpha$-helices (Figure 8A,B). Surface plots of LTP1 and LTP2 representatives are illustrated in Figure 2G, H. LTP1s and LTP2s share the same Cys signature and similar tertiary fold, but vary in amino acid sequence and disulfide bonding at the CXC motif [248,249]. LTP1 contains four $\alpha$-helices stabilized by four disulfide bonds (between CysI-CysVI, CysII-CysIII, CysIV-CysVII, and CysV-CysVIII) and a flexible C-terminal coil. In contrast to LTP1, LTP2 contains three extended helices, two single-turn helices, and four disulfide bonds between CysI-CysV, CysII-CysIII, CysIV-CysVII, and CysVI-CysVIII (Figure 8A) [249,250]. The helices in LTP1 and LTP2 form a hydrophobic cavity which accommodates a variety of lipids [251-254].
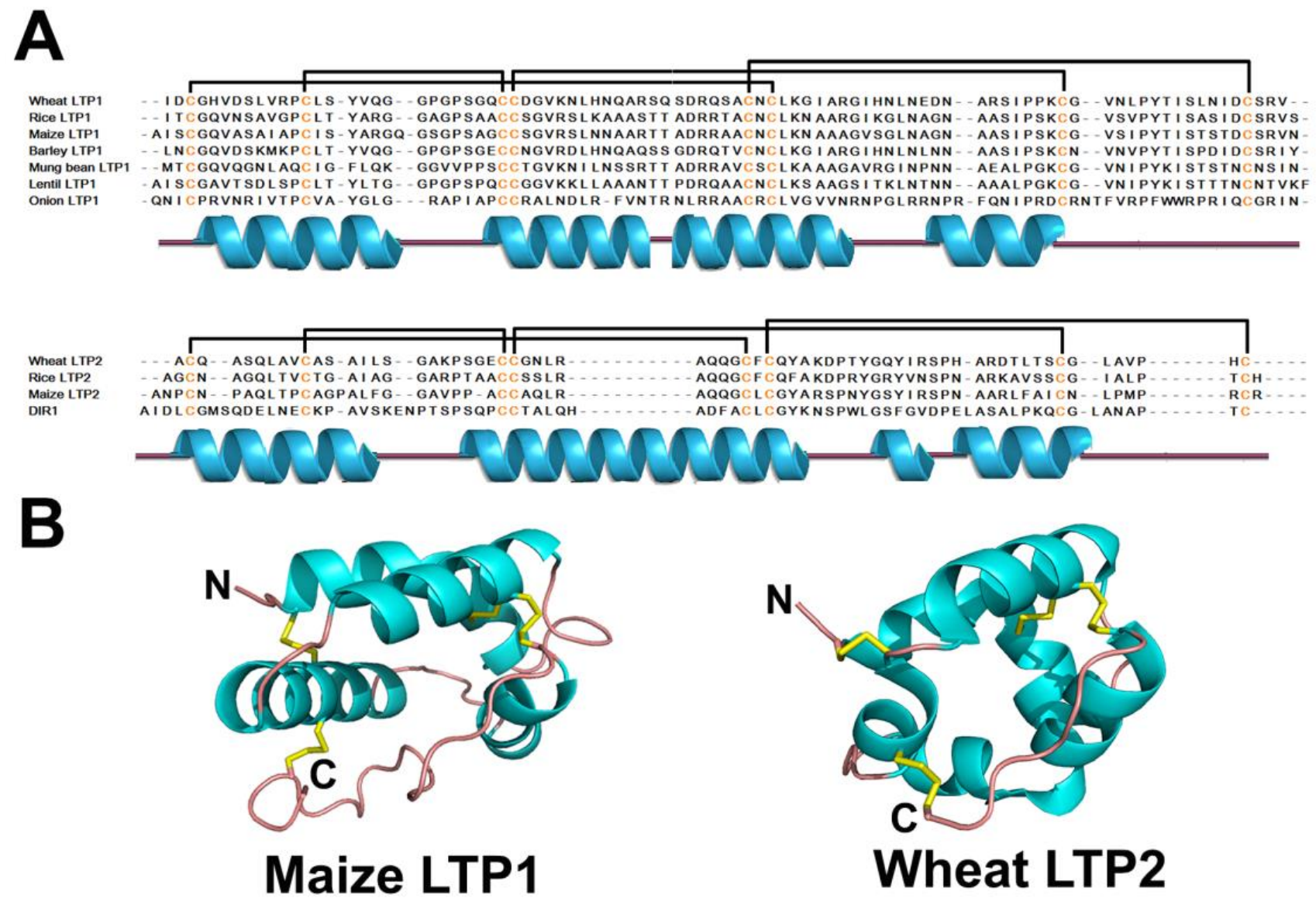

Figure 8. Sequences (A) and structures (B) of representative lipid transfer proteins. The secondary structure is represented by different colors: cyan- $\alpha$ helix; pink-random coil and yellow-disulfide bonds.

LTP1s and LTP2s have a conserved structure reported in rice [253,255,256], wheat [257,258], barley [259,260], maize [261,262], lentils [263], and mung beans [264]. Their lipid-binding properties can be modulated by subtle changes in their conserved global structure, as evidenced by structural and functional differences of LTP1s in tobacco, wheat, and maize [265]. Mutagenesis studies have revealed that different residues forming the hydrophobic cavity of LTP2 play various roles in maintaining structure and conferring function [266]. Although LTP2 is found to have a similar but smaller 
hydrophobic cavity compared to LTP1 [249,250,253,254,259], it is quite flexible and can accommodate voluminous sterol molecules [267].

\subsubsection{Structure-Function Relationship}

Plant LTPs inhibit the growth of bacterial and fungal pathogens to different degrees [243,246,268]. Transgenic expression of barley LTP2 in tobacco and Arabidopsis thaliana leaves endows higher tolerance to bacterial pathogens [269]. The antifungal activity of LTPs from Brassica and mung beans is found to be thermally, $\mathrm{pH}-$, and pepsin/trypsin treatment-stable [268].

Ace-AMP1 (onion LTP1; Figure 8A) isolated from onion seeds, exhibits a higher antimicrobial activity than the LTP extracted from radish seeds [89,243]. Ace-AMP1 shares a similar global fold as LTP1s, but does not possess a continuous cavity for lipid binding nor does it bind fluorescently labeled phospholipids in solution [252]. In addition, Ace-AMP1 does not exhibit characteristic LTP behavior, such as transferring lipids between membranes in vitro. While DIR1 from Arabidopsis thaliana shares similar structural and lipid binding properties with plant LTP2, it is distinguished by its acidic pI and ability to bind two long-chain fatty acid derivatives in its cavity, suggesting DIR 1 could be a new type of plant LTP [270]. The functions of plant LTPs, such as defensive signaling, cuticle deposition and plant defense, have been previously reviewed by Yeats and Rose [271].

\subsubsection{Mechanism of Action}

Initially, LTPs were reported to facilitate lipid transfer between membranes of vesicles or organelles in vitro [272,273]. However, later discoveries have shown that LTP1s are extracellular cell wall proteins, making in vivo intracellular lipid transfer activity unlikely [274,275]. Thus, LTPs promote membrane permeabilization in pathogens rather than host cells [246,276]. Although structural studies have shown that LTPs can "cage" lipid molecules in their hydrophobic cavity, a detailed mechanism of antimicrobial activity mediated by lipid transport remains unclear [271].

\subsection{Snakins}

Snakin-1 (63 aa) and snakin-2 (66 aa) are AMPs with 12 Cys isolated from potato tubers (Solanum tuberosum) [277,278] found to be active against fungal and bacterial pathogens at 1-20 $\mu \mathrm{M}$. Snakins induce the aggregation of both Gram-positive and Gram-negative bacteria and therefore, are recognized as components of constitutive and inducible plant defense barriers. The structure of snakin is predicted to have two long $\alpha$-helices with disulfide bonds between CysI-CysIX, CysII-CysVII, CysIII-CysIV, CysV-CysXI, CysVI-CysXII, and CysVIII-CysX, which demonstrates a small degree of structural similarity to thionins and $\alpha$-hairpinins [279].

A 64 aa homolog of snakin-2, also containing 12 Cys, was identified from the French bean to be a domain of a $42 \mathrm{kDa}$ Pro-rich protein with chitin-binding ability that is involved in plant-pathogen interactions [280]. Snakin-Z (31 aa), identified from the fruit of Zizyphus jujuba, contains a sequence similar to the C-terminal region of Snakin-2. It has antimicrobial activity against different bacterial and fungal strains at minimal concentrations $(7.65-28.8 \mu \mathrm{g} / \mathrm{mL})$ [281]. 


\subsection{Other Plant CRP-AMPs}

In addition to the different classes of CRP-AMPs mentioned above, there are several unclassified Cys-containing AMPs, such as Ps-AFP1, Ib-AMPs, Pp-AMPs, ToAMPs, and MiAMP1 that contain two to eight Cys. Ps-AFP1 (38 aa) from the pea Pisum sativum root contains two disulfide bonds between CysI-CysII and CysIII-CysIV, has been proposed to adopt a novel $\alpha \beta$-trumpet fold, and is capable of binding the cell wall of fungi [282]. Ib-AMPs1-4, purified from the seed of Impatiens balsamina, are four basic 20 aa peptides encoded by a single transcript. Ib-AMPs represent a novel class of AMPs that lack homology to other peptides [283,284]. They contain four Cys which share a common CC and CXXXC sequence motif and form two disulfide bonds between CysI-CysIII and CysII-CysIV. The structure of Ib-AMP1 is well-defined, with loops and turns stabilized by two disulfide bonds [285]. Ib-AMPs can inhibit the growth of a range of fungi and Gram-positive bacteria but is not cytotoxic to most Gram-negative bacteria or cultured human cells. Studies of Ib-AMP1 analogs without disulfide bonds have shown these bonds are not essential for its antimicrobial activity, and that Ib-AMP1 targets intracellular components instead of bacterial cell membranes [286].

Pp-AMP1 and Pp-AMP2 are two chitin-binding AMPs from the shoots of the Japanese bamboo Phyllostachys pubescens that have antimicrobial activity against pathogenic bacteria and fungi [287]. Pp-AMP1 contains four Cys in its 44 aa sequence, while Pp-AMP2 (45 aa) is composed of six Cys. Although they share relatively high sequence homology with thionins, especially the N-terminal continuous CC motif, their differences in the C-terminal sequence and Cys distribution pattern do not suggest Pp-AMPs are thionins. ToAMPs1-4 are four basic 38-44 aa AMPs identified from Taraxacum officinale flowers that have antifungal and antibacterial activity [288,289]. Sequence analysis has shown that ToAMP1, ToAMP2, and ToAMP4 possess a novel peptide motif of six Cys with a -CC- motif between CysII and CysIII, while ToAMP3 has eight Cys with a-CC-motif between CysVI and Cys VII.

MiAMP1 is a 76 aa basic AMP identified from the nut kernel of Macadamia integrifolia. MiAMP1 inhibits several plant microbial pathogens in vitro [290], yet presents no sequence homology with other plant AMPs and has a $\beta$-barrelin structure. The $\beta$-barrelins contain eight $\beta$-strands forming two Greek key motifs that are stabilized by three disulfide bonds. MiAMP1 has a structure similar to that of a yeast killer toxin from Williopsis mrakii, which inhibits $\beta$-glucan synthesis and thereby disturbs the cell wall of yeast. The structural similarity between these two peptides suggests a similar antimicrobial mode of action.

\subsection{Non-CRP Plant AMPs}

Although the majority of known plant AMPs are stabilized by multiple disulfide bonds, exceptions include Cn-AMPs, Cr-ACP1, as well as GRPs Pg-AMP1 and shepherins. All of these plant AMPs either do not contain Cys or contain only one and thus, possess high structural flexibility. Cn-AMP1 is a 9 aa Cys-free AMP identified from green coconut (Cocos nucifera) water with "promiscuous" activity, as it is antibacterial, antifungal, and immune stimulatory [291]. Cr-ACP1 is a 9 aa AMP from the seeds of Cycas revoluta with pro-apoptotic and antimicrobial activities [292]. A previous bioinformatics study suggests that these Cr-AMP1 activities are likely mediated by hydrogen bond-mediated DNA binding within cells. 
Pg-AMP1 is a 55 aa GRP extracted from seeds of the guava Psidium guajava. It contains 14 Gly and only one Cys [293] and inhibits the growth of both Gram-positive and Gram-negative bacteria, pathogens involved in urinary and gastro-intestinal infections [294]. Shepherins I and II are Gly- and His-rich AMPs identified from the roots of Shepherd's Purse, Capsella bursa-pastoris [295]. Shepherin I (28 aa) and shepherin II (38 aa) are produced from a single 120 aa propeptide precursor composed of an N-terminal signal peptide, shepherin I, a linker dipeptide, shepherin II, and a C-terminal peptide. Both exhibit antimicrobial activity against Gram-negative bacteria and fungi with an IC 50 of $2.5-8 \mu \mathrm{g} / \mathrm{mL}$.

\subsection{Mechanism of AMP Action}

AMPs are generally moderate-to-large size, positively charged, amphipathic CRPs. Structurally, AMPs fall into diverse and distinct groups (Table 1; Figure 2 ), including $\alpha$-helical peptides ( $\alpha$-hairpinin family and lipid transfer proteins), $\beta$-sheet peptides (hevein and knottin-type peptides) as well as mixed $\alpha$-helical and $\beta$-sheet peptides (thionins and plant defensins). Generally, the mechanism of AMP interaction with microbes is believed to be associated with cell lysis due to membrane disruption and/or peptide penetration of lipid membranes followed by attack of intracellular targets [14]. Various mechanistic models have been proposed, such as the barrel-stave model, toroidal pore model, and carpet model, in previous reviews by Barbosa, Rahnamaeian, and Nawrot [14,296,297]. Besides perturbing the lipid membrane, AMPs can also form ion channels, which can induce ion leakage (e.g., $\mathrm{K}^{+}$) in addition to other intracellular contents [298,299]. All of these actions lead to inhibition of microbial cell growth and cell death.

\section{Conclusions and Perspective}

A striking feature of plant AMPs is that the majority are families of CRPs, with each family sharing a characteristic motif. In turn, these cysteinyl motifs enable plant AMPs to organize into specific families with conserved structural folds that enable sequence variation of non-Cys residues encased in the same scaffold within a particular family to play multiple functions. This evolvable phenomenon is particularly evident in the family of knottins, and to a lesser extent, in the defensins. Knottins are known to play diverse roles, being antimicrobial, insecticidal, enzyme inhibitory, and agonistic/antagonistic to hormones. The ability of plant AMPs to tolerate hypervariable sequences using a conserved scaffold mimic is, in certain respects, similar to that of immunoglobulins, which recognize diverse targets by varying the sequence of complementary binding regions.

The presence of multiple disulfide bonds in a particular CRP family gives plant AMPs a compact structure and a specific scaffold. In turn, they confer stability against thermal and chemical denaturation and enzymatic degradation. These properties bode well for developing plant AMPs as potential therapeutics and for protection of crops through transgenic methods [300,301]. A cystine-stabilized structure opens the possibility to use it as a stable scaffold for grafting biological active peptides sequences to intracellular targets. Specifically, the backbone portions between cysteine residues can be modified to incorporate bioactive peptides which are normally unstable against digestive enzymes and other physiological conditions [302,303]. This technique has successfully been applied to graft bradykinin B1 antagonists onto kalata B1 as an orally active analgesic [221], human kallikrein-related 
peptidase 4 inhibitor onto sunflower trypsin inhibitor-1 [228], angiogenic peptides, laminin and osteopontin, onto Momordica cochinca cochinchinensis trypsin inhibitor-II [304] and melanocortin onto kalata B1 [305]. More importantly, these grafted peptides have been shown to possess the same biological property with similar potency as compared with the original bioactive peptides, as well as resistance to digestive enzymes due to the robust scaffold. In addition, plants AMPs, in particular defensin, have been shown to protect transgenic plants against microorganism infection. Expression of alfalfa antifungal peptide defensin, from the seeds of Medicago sativa, in transgenic potato plants has been found to provide resistance against phyto-pathogen Verticillium dahilae [77,306].

AMPs offer several advantages as compared to current antibiotic drugs as they represent a naturally occurring defense mechanism that has been used by plants for thousands of years in combating external pathogenic challenges. Most of the recent studies included in this review were focused on the anti-fungal and anti-bacterial effect of AMPs, while the anti-viral property of AMPs was still under-explored. Further investigation in tackling this issue is urgently warranted. Since plant AMPs have been identified in only a small fraction of plants, it is anticipated that many more plant AMPs, both in molecular form and sequence, will be forthcoming.

\section{Acknowledgments}

This work was supported in part by the Singapore National Research Foundation grant NRF-CRP8-2011-05.

\section{AuthorContributions}

All the authors contributed to manuscript preparation.

\section{Conflicts of Interest}

The authors declare no conflict of interest.

\section{References}

1. Stintzi, A.; Heitz, T.; Prasad, V.; Wiedemann-Merdinoglu, S.; Kauffmann, S.; Geoffroy, P.; Legrand, M.; Fritig, B. Plant "pathogenesis-related" proteins and their role in defense against pathogens. Biochimie 1993, 75, 687-706.

2. Sinha, M.; Singh, R.P.; Kushwaha, G.S.; Iqbal, N.; Singh, A.; Kaushik, S.; Kaur, P.; Sharma, S.; Singh, T.P. Current overview of allergens of plant pathogenesis related protein families. Sci. World J. 2014, 2014, 543195.

3. Ebrahim, S.; Usha, K.; Singh, B. Pathogenesis related (pr) proteins in plant defense mechanism. Sci. Against Microb. Pathog. 2011, 2, 1043-1054.

4. Sels, J.; Mathys, J.; De Coninck, B.M.; Cammue, B.P.; De Bolle, M.F. Plant pathogenesis-related (pr) proteins: A focus on pr peptides. Plant Physiol. Biochem. 2008, 46, 941-950.

5. Egorov, T.A.; Odintsova, T.I.; Pukhalsky, V.A.; Grishin, E.V. Diversity of wheat anti-microbial peptides. Peptides 2005, 26, 2064-2073.

6. Rao, A.G. Antimicrobial peptides. Mol. Plant Microbe Interact. 1995, 8, 6-13. 
7. Reddy, K.V.; Yedery, R.D.; Aranha, C. Antimicrobial peptides: Premises and promises. Int. J. Antimicrob. Agents 2004, 24, 536-547.

8. Montalban-Lopez, M.; Sanchez-Hidalgo, M.; Cebrian, R.; Maqueda, M. Discovering the bacterial circular proteins: Bacteriocins, cyanobactins, and pilins. J. Biol. Chem. 2012, 287, 27007-27013.

9. Tam, J.P.; Wong, C.T. Chemical synthesis of circular proteins. J. Biol. Chem. 2012, 287, 2702027025.

10. Hammami, R.; Ben Hamida, J.; Vergoten, G.; Fliss, I. Phytamp: A database dedicated to antimicrobial plant peptides. Nucleic Acids Res. 2009, 37, D963-D968.

11. Silverstein, K.A.; Moskal, W.A., Jr.; Wu, H.C.; Underwood, B.A.; Graham, M.A.; Town, C.D.; VandenBosch, K.A. Small cysteine-rich peptides resembling antimicrobial peptides have been under-predicted in plants. Plant. J. 2007, 51, 262-280.

12. Stec, B. Plant thionins--the structural perspective. Cell. Mol. Life Sci. 2006, 63, 1370-1385.

13. Garcia-Olmedo, F.; Molina, A.; Alamillo, J.M.; Rodriguez-Palenzuela, P. Plant defense peptides. Biopolymers 1998, 47, 479-491.

14. Nawrot, R.; Barylski, J.; Nowicki, G.; Broniarczyk, J.; Buchwald, W.; Gozdzicka-Jozefiak, A. Plant antimicrobial peptides. Folia Microbiol. (Praha) 2013, 59, 181-196.

15. Padovan, L.; Scocchi, M.; Tossi, A. Structural aspects of plant antimicrobial peptides. Curr. Protein Pept. Sci. 2010, 11, 210-219.

16. Lay, F.T.; Anderson, M.A. Defensins--components of the innate immune system in plants. Curr. Protein Pept. Sci. 2005, 6, 85-101.

17. Das, S.N.; Madhuprakash, J.; Sarma, P.V.; Purushotham, P.; Suma, K.; Manjeet, K.; Rambabu, S.; Gueddari, N.E.; Moerschbacher, B.M.; Podile, A.R. Biotechnological approaches for field applications of chitooligosaccharides (cos) to induce innate immunity in plants. Crit. Rev. Biotechnol. 2013, 35, 29-43.

18. Mander, L.N.; Liu, H.-W. Comprehensive Natural Products ii Chemistry and Biology; Elsevier Science: Oxford, England, 2010; p. 1.

19. Tavares, L.S.; Santos Mde, O.; Viccini, L.F.; Moreira, J.S.; Miller, R.N.; Franco, O.L. Biotechnological potential of antimicrobial peptides from flowers. Peptides 2008, 29, 1842-1851.

20. De Lucca, A.J.; Cleveland, T.E.; Wedge, D.E. Plant-derived antifungal proteins and peptides. Can. J. Microbiol. 2005, 51, 1001-1014.

21. Gruber, C.W.; Cemazar, M.; Anderson, M.A.; Craik, D.J. Insecticidal plant cyclotides and related cystine knot toxins. Toxicon 2007, 49, 561-575.

22. Craik, D.J. Host-defense activities of cyclotides. Toxins (Basel) 2012, 4, 139-156.

23. van der Weerden, N.L.; Bleackley, M.R.; Anderson, M.A. Properties and mechanisms of action of naturally occurring antifungal peptides. Cell. Mol. Life Sci. 2013, 70, 3545-3570.

24. Ng, T.B. Antifungal proteins and peptides of leguminous and non-leguminous origins. Peptides 2004, 25, 1215-1222.

25. Harris, F.; Dennison, S.R.; Phoenix, D.A. Anionic antimicrobial peptides from eukaryotic organisms. Curr. Protein Pept. Sci. 2009, 10, 585-606.

26. Wang, G.S.; Li, X.; Wang, Z. Apd2: The updated antimicrobial peptide database and its application in peptide design. Nucleic Acids Res. 2009, 37, D933-D937. 
27. Wang, Z.; Wang, G.S. Apd: The antimicrobial peptide database. Nucleic Acids Res. 2004, 32, D590-D592.

28. Piotto, S.P.; Sessa, L.; Concilio, S.; Iannelli, P. Yadamp: Yet another database of antimicrobial peptides. Int. J. Antimicrob. Agents 2012, 39, 346-351.

29. Sundararajan, V.S.; Gabere, M.N.; Pretorius, A.; Adam, S.; Christoffels, A.; Lehvaslaiho, M.; Archer, J.A.C.; Bajic, V.B. Dampd: A manually curated antimicrobial peptide database. Nucleic Acids Res. 2012, 40, D1108-D1112.

30. Fernandez de Caleya, R.; Gonzalez-Pascual, B.; Garcia-Olmedo, F.; Carbonero, P. Susceptibility of phytopathogenic bacteria to wheat purothionins in vitro. Appl. Microbiol. 1972, 23, 998-1000.

31. Ebrahimnesbat, F.; Behnke, S.; Kleinhofs, A.; Apel, K. Cultivar-related differences in the distribution of cell-wall-bound thionins in compatible and incompatible interactions between barley and powdery mildew. Planta 1989, 179, 203-210.

32. Evans, J.; Wang, Y.D.; Shaw, K.P.; Vernon, L.P. Cellular responses to pyrularia thionin are mediated by $\mathrm{Ca}^{2+}$ influx and phospholipase a2 activation and are inhibited by thionin tyrosine iodination. Proc. Natl. Acad. Sci. USA 1989, 86, 5849-5853.

33. Kramer, K.J.; Klassen, L.W.; Jones, B.L.; Speirs, R.D.; Kammer, A.E. Toxicity of purothionin and its homologues to the tobacco hornworm, manduca sexta (1.) (lepidoptera:Sphingidae). Toxicol. Appl. Pharmacol. 1979, 48, 179-183.

34. Balls, A.K.; Hale, W.S.; Harris, T.H. A crystalline protein obtained from a lipoprotein of wheat flour. Cereal Chem. 1942, 19, 951-961.

35. Ponz, F.; Paz-Ares, J.; Hernandez-Lucas, C.; Carbonero, P.; Garcia-Olmedo, F. Synthesis and processing of thionin precursors in developing endosperm from barley (hordeum vulgare 1.). EMBO J. 1983, 2, 1035-1040.

36. Steinmuller, K.; Batschauer, A.; Apel, K. Tissue-specific and light-dependent changes of chromatin organization in barley (hordeum vulgare). Eur. J. Biochem. 1986, 158, 519-525.

37. Gausing, K. Thionin genes specifically expressed in barley leaves. Planta 1987, 171, 241-246.

38. Epple, P.; Apel, K.; Bohlmann, H. An arabidopsis-thaliana thionin gene is inducible via a signal-transduction pathway different from that for pathogenesis-related proteins. Plant. Physiol. 1995, 109, 813-820.

39. Bohlmann, H.; Clausen, S.; Behnke, S.; Giese, H.; Hiller, C.; Reimann-Philipp, U.; Schrader, G.; Barkholt, V.; Apel, K. Leaf-specific thionins of barley-a novel class of cell wall proteins toxic to plant-pathogenic fungi and possibly involved in the defence mechanism of plants. EMBO J. 1988, 7, 1559-1565.

40. Andresen, I.; Becker, W.; Schluter, K.; Burges, J.; Parthier, B.; Apel, K. The identification of leaf thionin as one of the main jasmonate-induced proteins of barley (hordeum vulgare). Plant. Mol. Biol. 1992, 19, 193-204.

41. Penninckx, I.A.; Eggermont, K.; Terras, F.R.; Thomma, B.P.; De Samblanx, G.W.; Buchala, A.; Metraux, J.P.; Manners, J.M.; Broekaert, W.F. Pathogen-induced systemic activation of a plant defensin gene in arabidopsis follows a salicylic acid-independent pathway. Plant Cell. 1996, 8, 2309-2323. 
42. Castagnaro, A.; Marana, C.; Carbonero, P.; Garciaolmedo, F. Extreme divergence of a novel wheat thionin generated by a mutational burst specifically affecting the mature protein domain of the precursor. J. Mol. Biol. 1992, 224, 1003-1009.

43. Stec, B.; Markman, O.; Rao, U.; Heffron, G.; Henderson, S.; Vernon, L.P.; Brumfeld, V.; Teeter, M.M. Proposal for molecular mechanism of thionins deduced from physico-chemical studies of plant toxins. J. Pept. Res. 2004, 64, 210-224.

44. Rao, U.; Stec, B.; Teeter, M.M. Refinement of purothionins reveals solute particles important for lattice formation and toxicity. Part 1: Alpha1-purothionin revisited. Acta Crystallogr. D Biol. Crystallogr. 1995, 51, 904-913.

45. Stec, B.; Rao, U.; Teeter, M.M. Refinement of purothionins reveals solute particles important for lattice formation and toxicity. Part 2: Structure of beta-purothionin at 1.7 a resolution. Acta Crystallogr. D Biol. Crystallogr. 1995, 51, 914-924.

46. Milbradt, A.G.; Kerek, F.; Moroder, L.; Renner, C. Structural characterization of hellethionins from helleborus purpurascens. Biochemistry 2003, 42, 2404-2411.

47. Yamano, A.; Heo, N.H.; Teeter, M.M. Crystal structure of ser-22/ile-25 form crambin confirms solvent, side chain substate correlations. J. Biol. Chem. 1997, 272, 9597-9600.

48. Yamano, A.; Teeter, M.M. Correlated disorder of the pure pro22/leu25 form of crambin at $150 \mathrm{k}$ refined to 1.05-a resolution. J. Biol. Chem. 1994, 269, 13956-13965.

49. Hendrickson, W.A.; Teeter, M.M. Structure of the hydrophobic protein crambin determined directly from the anomalous scattering of sulfur. Nature 1981, 290, 107-113.

50. Ahn, H.C.; Juranic, N.; Macura, S.; Markley, J.L. Three-dimensional structure of the water-insoluble protein crambin in dodecylphosphocholine micelles and its minimal solvent-exposed surface. J. Am. Chem. Soc. 2006, 128, 4398-4404.

51. Schmidt, A.; Teeter, M.; Weckert, E.; Lamzin, V.S. Crystal structure of small protein crambin at 0.48 a resolution. Acta Crystallogr. Sect. F Struct. Biol. Cryst. Commun. 2010, 67, 424-428.

52. Chen, J.C.; Hanson, B.L.; Fisher, S.Z.; Langan, P.; Kovalevsky, A.Y. Direct observation of hydrogen atom dynamics and interactions by ultrahigh resolution neutron protein crystallography. Proc. Natl. Acad. Sci. USA 2012, 109, 15301-15306.

53. Jelsch, C.; Teeter, M.M.; Lamzin, V.; Pichon-Pesme, V.; Blessing, R.H.; Lecomte, C. Accurate protein crystallography at ultra-high resolution: Valence electron distribution in crambin. Proc. Natl. Acad. Sci. USA 2000, 97, 3171-3176.

54. Pal, A.; Debreczeni, J.E.; Sevvana, M.; Gruene, T.; Kahle, B.; Zeeck, A.; Sheldrick, G.M. Structures of viscotoxins a1 and b2 from european mistletoe solved using native data alone. Acta Crystallogr. D Biol. Crystallogr. 2008, 64, 985-992.

55. Romagnoli, S.; Fogolari, F.; Catalano, M.; Zetta, L.; Schaller, G.; Urech, K.; Giannattasio, M.; Ragona, L.; Molinari, H. Nmr solution structure of viscotoxin c1 from viscum album species coloratum ohwi: Toward a structure-function analysis of viscotoxins. Biochemistry 2003, 42, 12503-12510.

56. Coulon, A.; Mosbah, A.; Lopez, A.; Sautereau, A.M.; Schaller, G.; Urech, K.; Rouge, P.; Darbon, $\mathrm{H}$. Comparative membrane interaction study of viscotoxins $\mathrm{a} 3$, a2 and b from mistletoe (viscum album) and connections with their structures. Biochem. J. 2003, 374, 71-78. 
57. Romagnoli, S.; Ugolini, R.; Fogolari, F.; Schaller, G.; Urech, K.; Giannattasio, M.; Ragona, L.; Molinari, H. Nmr structural determination of viscotoxin a3 from viscum album 1. Biochem. J. 2000, 350 (Pt. 2), 569-577.

58. Debreczeni, J.E.; Girmann, B.; Zeeck, A.; Kratzner, R.; Sheldrick, G.M. Structure of viscotoxin a3: Disulfide location from weak sad data. Acta Crystallogr. D Biol. Crystallogr. 2003, 59, 2125-2132.

59. Clore, G.M.; Sukumaran, D.K.; Nilges, M.; Gronenborn, A.M. 3-dimensional structure of phoratoxin in solution - combined use of nuclear-magnetic-resonance, distance geometry, and restrained molecular-dynamics. Biochemistry 1987, 26, 1732-1745.

60. Mellstra, S.T.; Samuelss.G. Phoratoxin, a toxic protein from mistletoe phoradendron-tomentosum subsp. Macrophyllum (loranthaceae) - improvements in isolation procedure and further studies on properties. Eur. J. Biochem. 1973, 32, 143-147.

61. Johnson, K.A.; Kim, E.; Teeter, M.M.; Suh, S.W.; Stec, B. Crystal structure of alpha-hordothionin at 1.9 angstrom resolution. FEBS Lett. 2005, 579, 2301-2306.

62. Han, K.H.; Park, K.H.; Yoo, H.J.; Cha, H.; Suh, S.W.; Thomas, F.; Moon, T.S.; Kim, S.M. Determination of the three-dimensional structure of hordothionin-alpha by nuclear magnetic resonance. Biochem. J. 1996, 313 (Pt. 3), 885-892.

63. Vila-Perello, M.; Andreu, D. Characterization and structural role of disulfide bonds in a highly knotted thionin from pyrularia pubera. Biopolymers 2005, 80, 697-707.

64. Vila-Perello, M.; Sanchez-Vallet, A.; Garcia-Olmedo, F.; Molina, A.; Andreu, D. Structural dissection of a highly knotted peptide reveals minimal motif with antimicrobial activity. J. Biol. Chem. 2005, 280, 1661-1668.

65. Fujimura, M.; Ideguchi, M.; Minami, Y.; Watanabe, K.; Tadera, K. Purification, characterization, and sequencing of novel antimicrobial peptides, tu-amp 1 and tu-amp 2, from bulbs of tulip (tulipa gesneriana 1.). Biosci. Biotechnol. Biochem. 2004, 68, 571-577.

66. Florack, D.E.; Stiekema, W.J. Thionins: Properties, possible biological roles and mechanisms of action. Plant Mol. Biol. 1994, 26, 25-37.

67. Osorio e Castro, V.R.; Vernon, L.P. Hemolytic activity of thionin from pyrularia pubera nuts and snake venom toxins of naja naja species: Pyrularia thionin and snake venom cardiotoxin compete for the same membrane site. Toxicon 1989, 27, 511-517.

68. Hughes, P.; Dennis, E.; Whitecross, M.; Llewellyn, D.; Gage, P. The cytotoxic plant protein, beta-purothionin, forms ion channels in lipid membranes. J. Biol. Chem. 2000, 275, 823-827.

69. Carrasco, L.; Vazquez, D.; Hernandez-Lucas, C.; Carbonero, P.; Garcia-Olmedo, F. Thionins: Plant peptides that modify membrane permeability in cultured mammalian cells. Eur. J. Biochem. 1981, 116, 185-189.

70. Oka, T.; Murata, Y.; Nakanishi, T.; Yoshizumi, H.; Hayashida, H.; Ohtsuki, Y.; Toyoshima, K.; Hakura, A. Similarity, in molecular-structure and function, between the plant toxin purothionin and the mammalian pore-forming proteins. Mol. Biol. Evol. 1992, 9, 707-715.

71. Richard, J.A.; Kelly, I.; Marion, D.; Pezolet, M.; Auger, M. Interaction between beta-purothionin and dimyristoylphosphatidylglycerol: A p-31-nmr and infrared spectroscopic study. Biophysic. J. 2002, 83, 2074-2083. 
72. Richard, J.A.; Kelly, I.; Marion, D.; Auger, M.; Pezolet, M. Structure of beta-purothionin in membranes: A two-dimensional infrared correlation spectroscopy study. Biochemistry 2005, 44, $52-61$.

73. Wada, K.; Ozaki, Y.; Matsubara, H.; Yoshizumi, H. Studies on purothionin by chemical modifications. J. Biochem. 1982, 91, 257-263.

74. Fracki, W.S.; Li, D.; Owen, N.; Perry, C.; Naisbitt, G.H.; Vernon, L.P. Role of tyr and trp in membrane responses of pyrularia thionin determined by optical and nmr spectra following tyr iodination and trp modification. Toxicon 1992, 30, 1427-1440.

75. Rao, A.G.; Hassan, M.; Hempel, J. Validation of the structure-function properties of alpha-hordothionin and derivatives through protein modeling. Protein Eng. 1993, 6, 117-117.

76. Pelegrini, P.B.; Franco, O.L. Plant gamma-thionins: Novel insights on the mechanism of action of a multi-functional class of defense proteins. Int. J. Biochem. Cell. Biol. 2005, 37, 2239-2253.

77. Gao, A.G.; Hakimi, S.M.; Mittanck, C.A.; Wu, Y.; Woerner, B.M.; Stark, D.M.; Shah, D.M.; Liang, J.; Rommens, C.M. Fungal pathogen protection in potato by expression of a plant defensin peptide. Nat. Biotechnol. 2000, 18, 1307-1310.

78. Terras, F.R.; Schoofs, H.M.; De Bolle, M.F.; Van Leuven, F.; Rees, S.B.; Vanderleyden, J.; Cammue, B.P.; Broekaert, W.F. Analysis of two novel classes of plant antifungal proteins from radish (raphanus sativus 1.) seeds. J. Biol. Chem. 1992, 267, 15301-15309.

79. Terras, F.R.; Eggermont, K.; Kovaleva, V.; Raikhel, N.V.; Osborn, R.W.; Kester, A.; Rees, S.B.; Torrekens, S.; Van Leuven, F.; Vanderleyden, J., et al. Small cysteine-rich antifungal proteins from radish: Their role in host defense. Plant Cell. 1995, 7, 573-588.

80. Fant, F.; Vranken, W.F.; Borremans, F.A. The three-dimensional solution structure of aesculus hippocastanum antimicrobial protein 1 determined by $1 \mathrm{~h}$ nuclear magnetic resonance. Proteins 1999, 37, 388-403.

81. Fant, F.; Vranken, W.; Broekaert, W.; Borremans, F. Determination of the three-dimensional solution structure of raphanus sativus antifungal protein 1 by $1 \mathrm{~h}$ nmr. J. Mol. Biol. 1998, 279, 257-270.

82. Fujimura, M.; Minami, Y.; Watanabe, K.; Tadera, K. Purification, characterization, and sequencing of a novel type of antimicrobial peptides, fa-amp1 and fa-amp2, from seeds of buckwheat (Fagopyrum esculentum Moench.). Biosci. Biotechnol. Biochem. 2003, 67, 1636-1642.

83. Sitaram, N. Antimicrobial peptides with unusual amino acid compositions and unusual structures. Curr. Med. Chem. 2006, 13, 679-696.

84. Bloch, C., Jr.; Richardson, M. A new family of small (5 kda) protein inhibitors of insect alpha-amylases from seeds or sorghum (Sorghum bicolar (L.) Moench.) have sequence homologies with wheat gamma-purothionins. FEBS Lett. 1991, 279, 101-104.

85. Wijaya, R.; Neumann, G.M.; Condron, R.; Hughes, A.B.; Polya, G.M. Defense proteins from seed of cassia fistula include a lipid transfer protein homologue and a protease inhibitory plant defensin. Plant Sci. 2000, 159, 243-255.

86. Colilla, F.J.; Rocher, A.; Mendez, E. Gamma-purothionins: Amino acid sequence of two polypeptides of a new family of thionins from wheat endosperm. FEBS Lett. 1990, 270, 191-194. 
87. Mendez, E.; Moreno, A.; Colilla, F.; Pelaez, F.; Limas, G.G.; Mendez, R.; Soriano, F.; Salinas, M.; de Haro, C. Primary structure and inhibition of protein synthesis in eukaryotic cell-free system of a novel thionin, gamma-hordothionin, from barley endosperm. Eur. J. Biochem. 1990, 194, 533-539.

88. Bruix, M.; Jimenez, M.A.; Santoro, J.; Gonzalez, C.; Colilla, F.J.; Mendez, E.; Rico, M. Solution structure of gamma 1-h and gamma 1-p thionins from barley and wheat endosperm determined by 1h-nmr: A structural motif common to toxic arthropod proteins. Biochemistry 1993, 32, 715-724.

89. Broekaert, W.F.; Terras, F.R.G.; Cammue, B.P.A.; Osborn, R.W. Plant defensins - novel antimicrobial peptides as components of the host-defense system. Plant Physiol. 1995, 108, $1353-1358$.

90. Franco, O.L.; Murad, A.M.; Leite, J.R.; Mendes, P.A.; Prates, M.V.; Bloch, C., Jr. Identification of a cowpea gamma-thionin with bactericidal activity. FEBS J. 2006, 273, 3489-3497.

91. Moreno, M.; Segura, A.; Garcia-Olmedo, F. Pseudothionin-st1, a potato peptide active against potato pathogens. Eur. J. Biochem. 1994, 223, 135-139.

92. Chiang, C.C.; Hadwiger, L.A. The fusarium solani-induced expression of a pea gene family encoding high cysteine content proteins. Mol. Plant Microbe Interact. 1991, 4, 324-331.

93. Park, H.C.; Kang, Y.H.; Chun, H.J.; Koo, J.C.; Cheong, Y.H.; Kim, C.Y.; Kim, M.C.; Chung, W.S.; Kim, J.C.; Yoo, J.H.; et al. Characterization of a stamen-specific cdna encoding a novel plant defensin in chinese cabbage. Plant Mol. Biol. 2002, 50, 59-69.

94. Milligan, S.B.; Gasser, C.S. Nature and regulation of pistil-expressed genes in tomato. Plant Mol. Biol. 1995, 28, 691-711.

95. Lay, F.T.; Brugliera, F.; Anderson, M.A. Isolation and properties of floral defensins from ornamental tobacco and petunia. Plant Physiol. 2003, 131, 1283-1293.

96. Sharma, P.; Lonneborg, A. Isolation and characterization of a cdna encoding a plant defensin-like protein from roots of norway spruce. Plant Mol. Biol. 1996, 31, 707-712.

97. Finkina, E.I.; Shramova, E.I.; Tagaev, A.A.; Ovchinnikova, T.V. A novel defensin from the lentil lens culinaris seeds. Biochem. Biophys. Res. Commun. 2008, 371, 860-865.

98. Bontems, F.; Roumestand, C.; Boyot, P.; Gilquin, B.; Doljansky, Y.; Menez, A.; Toma, F. Three-dimensional structure of natural charybdotoxin in aqueous solution by 1h-nmr. Charybdotoxin possesses a structural motif found in other scorpion toxins. Eur. J. Biochem. 1991, 196, 19-28.

99. Cornet, B.; Bonmatin, J.M.; Hetru, C.; Hoffmann, J.A.; Ptak, M.; Vovelle, F. Refined three-dimensional solution structure of insect defensin a. Structure 1995, 3, 435-448.

100. Broekaert, W.F.; Cammue, B.P.A.; DeBolle, M.F.C.; Thevissen, K.; DeSamblanx, G.W.; Osborn, R.W. Antimicrobial peptides from plants. Crit. Rev. Plant. Sci. 1997, 16, 297-323.

101. Thomma, B.P.; Cammue, B.P.; Thevissen, K. Plant defensins. Planta 2002, 216, 193-202.

102. Raj, P.A.; Dentino, A.R. Current status of defensins and their role in innate and adaptive immunity. FEMS Microbiol. Lett. 2002, 206, 9-18.

103. Bulet, P.; Hetru, C.; Dimarcq, J.L.; Hoffmann, D. Antimicrobial peptides in insects; structure and function. Dev. Comp. Immunol. 1999, 23, 329-344.

104. Carvalho Ade, O.; Gomes, V.M. Plant defensins and defensin-like peptides - biological activities and biotechnological applications. Curr. Pharm. Des. 2011, 17, 4270-4293. 
105. Yang, Y.F.; Cheng, K.C.; Tsai, P.H.; Liu, C.C.; Lee, T.R.; Lyu, P.C. Alanine substitutions of noncysteine residues in the cysteine-stabilized alphabeta motif. Protein Sci. 2009, 18, 1498-1506.

106. Lay, F.T.; Schirra, H.J.; Scanlon, M.J.; Anderson, M.A.; Craik, D.J. The three-dimensional solution structure of nad1, a new floral defensin from nicotiana alata and its application to a homology model of the crop defense protein alfafp. J. Mol. Biol. 2003, 325, 175-188.

107. Chen, K.C.; Lin, C.Y.; Kuan, C.C.; Sung, H.Y.; Chen, C.S. A novel defensin encoded by a mungbean cdna exhibits insecticidal activity against bruchid. J. Agric. Food Chem. 2002, 50, 7258-7263.

108. Janssen, B.J.; Schirra, H.J.; Lay, F.T.; Anderson, M.A.; Craik, D.J. Structure of petunia hybrida defensin 1, a novel plant defensin with five disulfide bonds. Biochemistry 2003, 42, 8214-8222.

109. Mendez, E.; Rocher, A.; Calero, M.; Girbes, T.; Citores, L.; Soriano, F. Primary structure of omega-hordothionin, a member of a novel family of thionins from barley endosperm, and its inhibition of protein synthesis in eukaryotic and prokaryotic cell-free systems. Eur. J. Biochem. 1996, 239, 67-73.

110. Song, X.; Zhou, Z.; Wang, J.; Wu, F.; Gong, W. Purification, characterization and preliminary crystallographic studies of a novel plant defensin from pachyrrhizus erosus seeds. Acta Crystallogr. D Biol. Crystallogr. 2004, 60, 1121-1124.

111. Song, X.; Zhang, M.; Zhou, Z.; Gong, W. Ultra-high resolution crystal structure of a dimeric defensin spe10. FEBS Lett. 2011, 585, 300-306.

112. Spelbrink, R.G.; Dilmac, N.; Allen, A.; Smith, T.J.; Shah, D.M.; Hockerman, G.H. Differential antifungal and calcium channel-blocking activity among structurally related plant defensins. Plant Physiol. 2004, 135, 2055-2067.

113. Osborn, R.W.; De Samblanx, G.W.; Thevissen, K.; Goderis, I.; Torrekens, S.; Van Leuven, F.; Attenborough, S.; Rees, S.B.; Broekaert, W.F. Isolation and characterisation of plant defensins from seeds of asteraceae, fabaceae, hippocastanaceae and saxifragaceae. FEBS Lett. 1995, 368, 257-262.

114. Almeida, M.S.; Cabral, K.M.; Kurtenbach, E.; Almeida, F.C.; Valente, A.P. Solution structure of pisum sativum defensin 1 by high resolution nmr: Plant defensins, identical backbone with different mechanisms of action. J. Mol. Biol. 2002, 315, 749-757.

115. Zhang, Y.; Lewis, K. Fabatins: New antimicrobial plant peptides. FEMS Microbiol. Lett. 1997, $149,59-64$.

116. Garciaolmedo, F.; Carbonero, P.; Hernandezlucas, C.; Pazares, J.; Ponz, F.; Vicente, O.; Sierra, J.M. Inhibition of eukaryotic cell-free protein-synthesis by thionins from wheat endosperm. Biochim. Biophys. Acta 1983, 740, 52-56.

117. Pelegrini, P.B.; Lay, F.T.; Murad, A.M.; Anderson, M.A.; Franco, O.L. Novel insights on the mechanism of action of alpha-amylase inhibitors from the plant defensin family. Proteins $\mathbf{2 0 0 8}$, 73, 719-729.

118. Dos Santos, I.S.; Carvalho Ade, O.; de Souza-Filho, G.A.; do Nascimento, V.V.; Machado, O.L.; Gomes, V.M. Purification of a defensin isolated from vigna unguiculata seeds, its functional expression in escherichia coli, and assessment of its insect alpha-amylase inhibitory activity. Protein Expr. Purif. 2010, 71, 8-15. 
119. Carvalho Ade, O.; Gomes, V.M. Plant defensins--prospects for the biological functions and biotechnological properties. Peptides 2009, 30, 1007-1020.

120. Kushmerick, C.; de Souza Castro, M.; Santos Cruz, J.; Bloch, C., Jr.; Beirao, P.S. Functional and structural features of gamma-zeathionins, a new class of sodium channel blockers. FEBS Lett. 1998, 440, 302-306.

121. Melo, F.R.; Rigden, D.J.; Franco, O.L.; Mello, L.V.; Ary, M.B.; Grossi de Sa, M.F.; Bloch, C., Jr. Inhibition of trypsin by cowpea thionin: Characterization, molecular modeling, and docking. Proteins 2002, 48, 311-319.

122. Huang, G.J.; Lai, H.C.; Chang, Y.S.; Sheu, M.J.; Lu, T.L.; Huang, S.S.; Lin, Y.H. Antimicrobial, dehydroascorbate reductase, and monodehydroascorbate reductase activities of defensin from sweet potato [ipomoea batatas (1.) lam. 'Tainong 57'] storage roots. J. Agric. Food Chem. 2008, 56, 2989-2995.

123. Chen, Z.; Gallie, D.R. Dehydroascorbate reductase affects leaf growth, development, and function. Plant Physiol. 2006, 142, 775-787.

124. Thevissen, K.; Osborn, R.W.; Acland, D.P.; Broekaert, W.F. Specific binding sites for an antifungal plant defensin from dahlia (dahlia merckii) on fungal cells are required for antifungal activity. Mol. Plant Microbe Interact. 2000, 13, 54-61.

125. Thevissen, K.; Warnecke, D.C.; Francois, I.E.; Leipelt, M.; Heinz, E.; Ott, C.; Zahringer, U.; Thomma, B.P.; Ferket, K.K.; Cammue, B.P. Defensins from insects and plants interact with fungal glucosylceramides. J. Biol. Chem. 2004, 279, 3900-3905.

126. Thevissen, K.; Ghazi, A.; De Samblanx, G.W.; Brownlee, C.; Osborn, R.W.; Broekaert, W.F. Fungal membrane responses induced by plant defensins and thionins. J. Biol. Chem. 1996, 271, 15018-15025.

127. Thevissen, K.; Terras, F.R.; Broekaert, W.F. Permeabilization of fungal membranes by plant defensins inhibits fungal growth. Appl. Environ. Microbiol. 1999, 65, 5451-5458.

128. Van der Weerden, N.L.; Hancock, R.E.; Anderson, M.A. Permeabilization of fungal hyphae by the plant defensin nad1 occurs through a cell wall-dependent process. J. Biol. Chem. 2010, 285, 37513-37520.

129. Van der Weerden, N.L.; Lay, F.T.; Anderson, M.A. The plant defensin, nad1, enters the cytoplasm of fusarium oxysporum hyphae. J. Biol. Chem. 2008, 283, 14445-14452.

130. Hayes, B.M.; Bleackley, M.R.; Wiltshire, J.L.; Anderson, M.A.; Traven, A.; van der Weerden, N.L. Identification and mechanism of action of the plant defensin nad1 as a new member of the antifungal drug arsenal against candida albicans. Antimicrob. Agents Chemother. 2013, 57, 3667-3675.

131. De Coninck, B.; Cammue, B.P.A.; Thevissen, K. Modes of antifungal action and in planta functions of plant defensins and defensin-like peptides. Fungal Biol. Rev. 2013, 26, 109-120.

132. Gachomo, E.W.; Jimenez-Lopez, J.C.; Kayode, A.P.; Baba-Moussa, L.; Kotchoni, S.O. Structural characterization of plant defensin protein superfamily. Mol. Biol. Rep. 2012, 39, 4461-4469.

133. Beintema, J.J. Structural features of plant chitinases and chitin-binding proteins. FEBS Lett. 1994, $350,159-163$. 
134. Jimenez-Barbero, J.; Javier Canada, F.; Asensio, J.L.; Aboitiz, N.; Vidal, P.; Canales, A.; Groves, P.; Gabius, H.J.; Siebert, H.C. Hevein domains: An attractive model to study carbohydrate-protein interactions at atomic resolution. Adv. Carbohydr. Chem. Biochem. 2006, 60, 303-354.

135. Kini, S.G.; Nguyen, P.Q.; Weissbach, S.; Mallagaray, A.; Shin, J.; Yoon, H.S.; Tam, J.P. Studies on the chitin binding property of novel cysteine-rich peptides from alternanthera sessilis. Biochemistry 2015, 54, 6639-6649.

136. Archer, B.L. The proteins of hevea brasiliensis latex. 4. Isolation and characterization of crystalline hevein. Biochem. J. 1960, 75, 236-240.

137. Van Parijs, J.; Broekaert, W.F.; Goldstein, I.J.; Peumans, W.J. Hevein: An antifungal protein from rubber-tree (Hevea brasiliensis) latex. Planta 1991, 183, 258-264.

138. Diaz-Perales, A.; Collada, C.; Blanco, C.; Sanchez-Monge, R.; Carrillo, T.; Aragoncillo, C.; Salcedo, G. Cross-reactions in the latex-fruit syndrome: A relevant role of chitinases but not of complex asparagine-linked glycans. J. Allergy Clin. Immunol. 1999, 104, 681-687.

139. Blanco, C.; Diaz-Perales, A.; Collada, C.; Sanchez-Monge, R.; Aragoncillo, C.; Castillo, R.; Ortega, N.; Alvarez, M.; Carrillo, T.; Salcedo, G. Class i chitinases as potential panallergens involved in the latex-fruit syndrome. J. Allergy Clin. Immunol. 1999, 103, 507-513.

140. Gidrol, X.; Chrestin, H.; Tan, H.L.; Kush, A. Hevein, a lectin-like protein from hevea brasiliensis (rubber tree) is involved in the coagulation of latex. J. Biol. Chem. 1994, 269, 9278-9283.

141. Peumans, W.J.; Van Damme, E.J. Plant lectins: Specific tools for the identification, isolation, and characterization of o-linked glycans. Crit. Rev. Biochem. Mol. Biol. 1998, 33, 209-258.

142. Asensio, J.L.; Siebert, H.C.; von Der Lieth, C.W.; Laynez, J.; Bruix, M.; Soedjanaamadja, U.M.; Beintema, J.J.; Canada, F.J.; Gabius, H.J.; Jimenez-Barbero, J. Nmr investigations of protein-carbohydrate interactions: Studies on the relevance of trp/tyr variations in lectin binding sites as deduced from titration microcalorimetry and $\mathrm{nmr}$ studies on hevein domains. Determination of the nmr structure of the complex between pseudohevein and n,n',n"-triacetylchitotriose. Proteins 2000, 40, 218-236.

143. Lipkin, A.; Anisimova, V.; Nikonorova, A.; Babakov, A.; Krause, E.; Bienert, M.; Grishin, E.; Egorov, T. An antimicrobial peptide ar-amp from amaranth (Amaranthus retroflexus L.) seeds. Phytochemistry 2005, 66, 2426-2431.

144. Andreev, Y.A.; Korostyleva, T.V.; Slavokhotova, A.A.; Rogozhin, E.A.; Utkina, L.L.; Vassilevski, A.A.; Grishin, E.V.; Egorov, T.A.; Odintsova, T.I. Genes encoding hevein-like defense peptides in wheat: Distribution, evolution, and role in stress response. Biochimie 2012, 94, 1009-1016.

145. Van den Bergh, K.P.; Rouge, P.; Proost, P.; Coosemans, J.; Krouglova, T.; Engelborghs, Y.; Peumans, W.J.; Van Damme, E.J. Synergistic antifungal activity of two chitin-binding proteins from spindle tree (Euonymus europaeus L.). Planta 2004, 219, 221-232.

146. Asensio, J.L.; Canada, F.J.; Bruix, M.; Gonzalez, C.; Khiar, N.; Rodriguez-Romero, A.; Jimenez-Barbero, J. Nmr investigations of protein-carbohydrate interactions: Refined three-dimensional structure of the complex between hevein and methyl beta-chitobioside. Glycobiology 1998, 8, 569-577.

147. Harata, K.; Muraki, M. Crystal structures of urtica dioica agglutinin and its complex with tri-n-acetylchitotriose. J. Mol. Biol. 2000, 297, 673-681. 
148. Broekaert, W.F.; Marien, W.; Terras, F.R.; De Bolle, M.F.; Proost, P.; Van Damme, J.; Dillen, L.; Claeys, M.; Rees, S.B.; Vanderleyden, J.; et al. Antimicrobial peptides from amaranthus caudatus seeds with sequence homology to the cysteine/glycine-rich domain of chitin-binding proteins. Biochemistry 1992, 31, 4308-4314.

149. Martins, J.C.; Maes, D.; Loris, R.; Pepermans, H.A.; Wyns, L.; Willem, R.; Verheyden, P. H nmr study of the solution structure of ac-amp2, a sugar binding antimicrobial protein isolated from amaranthus caudatus. J. Mol. Biol. 1996, 258, 322-333.

150. Aboitiz, N.; Vila-Perello, M.; Groves, P.; Asensio, J.L.; Andreu, D.; Canada, F.J.; Jimenez-Barbero, J. Nmr and modeling studies of protein-carbohydrate interactions: Synthesis, three-dimensional structure, and recognition properties of a minimum hevein domain with binding affinity for chitooligosaccharides. ChemBioChem 2004, 5, 1245-1255.

151. Koo, J.C.; Lee, S.Y.; Chun, H.J.; Cheong, Y.H.; Choi, J.S.; Kawabata, S.; Miyagi, M.; Tsunasawa, S.; Ha, K.S.; Bae, D.W.; et al. Two hevein homologs isolated from the seed of pharbitis nil 1. Exhibit potent antifungal activity. Biochim. Biophys. Acta 1998, 1382, 80-90.

152. Lee, O.S.; Lee, B.; Park, N.; Koo, J.C.; Kim, Y.H.; Prasad, D.T.; Karigar, C.; Chun, H.J.; Jeong, B.R.; Kim, D.H.; et al. Pn-amps, the hevein-like proteins from pharbitis nil confers disease resistance against phytopathogenic fungi in tomato, lycopersicum esculentum. Phytochemistry 2003, 62, 1073-1079.

153. Koo, J.C.; Chun, H.J.; Park, H.C.; Kim, M.C.; Koo, Y.D.; Koo, S.C.; Ok, H.M.; Park, S.J.; Lee, S.H.; Yun, D.J.; et al. Over-expression of a seed specific hevein-like antimicrobial peptide from pharbitis nil enhances resistance to a fungal pathogen in transgenic tobacco plants. Plant Mol. Biol. 2002, 50, 441-452.

154. Li, S.S.; Claeson, P. Cys/gly-rich proteins with a putative single chitin-binding domain from oat (Avena sativa) seeds. Phytochemistry 2003, 63, 249-255.

155. Huang, R.H.; Xiang, Y.; Liu, X.Z.; Zhang, Y.; Hu, Z.; Wang, D.C. Two novel antifungal peptides distinct with a five-disulfide motif from the bark of eucommia ulmoides oliv. FEBS Lett. 2002, 521, 87-90.

156. Huang, R.H.; Xiang, Y.; Tu, G.Z.; Zhang, Y.; Wang, D.C. Solution structure of eucommia antifungal peptide: A novel structural model distinct with a five-disulfide motif. Biochemistry 2004, 43, 6005-6012.

157. Xiang, Y.; Huang, R.H.; Liu, X.Z.; Zhang, Y.; Wang, D.C. Crystal structure of a novel antifungal protein distinct with five disulfide bridges from eucommia ulmoides oliver at an atomic resolution. J. Struct. Biol 2004, 148, 86-97.

158. Odintsova, T.I.; Vassilevski, A.A.; Slavokhotova, A.A.; Musolyamov, A.K.; Finkina, E.I.; Khadeeva, N.V.; Rogozhin, E.A.; Korostyleva, T.V.; Pukhalsky, V.A.; Grishin, E.V.; et al. A novel antifungal hevein-type peptide from triticum kiharae seeds with a unique 10-cysteine motif. FEBS J. 2009, 276, 4266-4275.

159. Dubovskii, P.V.; Vassilevski, A.A.; Slavokhotova, A.A.; Odintsova, T.I.; Grishin, E.V.; Egorov, T.A.; Arseniev, A.S. Solution structure of a defense peptide from wheat with a 10-cysteine motif. Biochem. Biophys. Res. Commun. 2011, 411, 14-18. 
160. Van den Bergh, K.P.; Proost, P.; Van Damme, J.; Coosemans, J.; Van Damme, E.J.; Peumans, W.J. Five disulfide bridges stabilize a hevein-type antimicrobial peptide from the bark of spindle tree (Euonymus europaeus L.). FEBS Lett. 2002, 530, 181-185.

161. Chavez, M.I.; Vila-Perello, M.; Canada, F.J.; Andreu, D.; Jimenez-Barbero, J. Effect of a serine-to-aspartate replacement on the recognition of chitin oligosaccharides by truncated hevein. A 3d view by using nmr. Carbohydr. Res. 2010, 345, 1461-1468.

162. Espinosa, J.F.; Asensio, J.L.; Garcia, J.L.; Laynez, J.; Bruix, M.; Wright, C.; Siebert, H.C.; Gabius, H.J.; Canada, F.J.; Jimenez-Barbero, J. Nmr investigations of protein-carbohydrate interactions binding studies and refined three-dimensional solution structure of the complex between the $b$ domain of wheat germ agglutinin and n,n',n"-triacetylchitotriose. Eur. J. Biochem. 2000, 267, 3965-3978.

163. Muraki, M. The importance of $\mathrm{ch} / \mathrm{pi}$ interactions to the function of carbohydrate binding proteins. Protein Pept. Lett. 2002, 9, 195-209.

164. Chavez, M.I.; Andreu, C.; Vidal, P.; Aboitiz, N.; Freire, F.; Groves, P.; Asensio, J.L.; Asensio, G.; Muraki, M.; Canada, F.J.; et al. On the importance of carbohydrate-aromatic interactions for the molecular recognition of oligosaccharides by proteins: Nmr studies of the structure and binding affinity of acamp2-like peptides with non-natural naphthyl and fluoroaromatic residues. Chemistry 2005, 11, 7060-7074.

165. Slavokhotova, A.A.; Naumann, T.A.; Price, N.P.; Rogozhin, E.A.; Andreev, Y.A.; Vassilevski, A.A.; Odintsova, T.I. Novel mode of action of plant defense peptides - hevein-like antimicrobial peptides from wheat inhibit fungal metalloproteases. FEBS J. 2014, 281, 4754-4764.

166. Pallaghy, P.K.; Nielsen, K.J.; Craik, D.J.; Norton, R.S. A common structural motif incorporating a cystine knot and a triple-stranded beta-sheet in toxic and inhibitory polypeptides. Protein Sci. 1994, 3, 1833-1839.

167. Franco, O.L. Peptide promiscuity: An evolutionary concept for plant defense. FEBS Lett. 2011, 585, 995-1000.

168. Rees, D.C.; Lipscomb, W.N. Refined crystal structure of the potato inhibitor complex of carboxypeptidase a at 2.5 a resolution. J. Mol. Biol. 1982, 160, 475-498.

169. McDonald, N.Q.; Hendrickson, W.A. A structural superfamily of growth factors containing a cystine knot motif. Cell 1993, 73, 421-424.

170. Craik, D.J.; Daly, N.L.; Bond, T.; Waine, C. Plant cyclotides: A unique family of cyclic and knotted proteins that defines the cyclic cystine knot structural motif. J. Mol. Biol. 1999, 294, 1327-1336.

171. Gruber, C.W.; Elliott, A.G.; Ireland, D.C.; Delprete, P.G.; Dessein, S.; Goransson, U.; Trabi, M.; Wang, C.K.; Kinghorn, A.B.; Robbrecht, E.; et al. Distribution and evolution of circular miniproteins in flowering plants. Plant Cell. 2008, 20, 2471-2483.

172. Poth, A.G.; Mylne, J.S.; Grassl, J.; Lyons, R.E.; Millar, A.H.; Colgrave, M.L.; Craik, D.J. Cyclotides associate with leaf vasculature and are the products of a novel precursor in petunia (solanaceae). J. Biol. Chem. 2012, 287, 27033-27046. 
173. Nguyen, G.K.; Zhang, S.; Nguyen, N.T.; Nguyen, P.Q.; Chiu, M.S.; Hardjojo, A.; Tam, J.P. Discovery and characterization of novel cyclotides originated from chimeric precursors consisting of albumin-1 chain a and cyclotide domains in the fabaceae family. J. Biol. Chem. 2011, 286, $24275-24287$.

174. Poth, A.G.; Colgrave, M.L.; Lyons, R.E.; Daly, N.L.; Craik, D.J. Discovery of an unusual biosynthetic origin for circular proteins in legumes. Proc. Natl. Acad. Sci. USA 2011, 108, 10127-10132.

175. Mylne, J.S.; Chan, L.Y.; Chanson, A.H.; Daly, N.L.; Schaefer, H.; Bailey, T.L.; Nguyencong, P.; Cascales, L.; Craik, D.J. Cyclic peptides arising by evolutionary parallelism via asparaginyl-endopeptidase-mediated biosynthesis. Plant Cell. 2012, 24, 2765-2778.

176. Nguyen, G.K.; Lian, Y.; Pang, E.W.; Nguyen, P.Q.; Tran, T.D.; Tam, J.P. Discovery of linear cyclotides in monocot plant panicum laxum of poaceae family provides new insights into evolution and distribution of cyclotides in plants. J. Biol. Chem. 2012, 288, 3370-3380.

177. Ireland, D.C.; Colgrave, M.L.; Nguyencong, P.; Daly, N.L.; Craik, D.J. Discovery and characterization of a linear cyclotide from viola odorata: Implications for the processing of circular proteins. J. Mol. Biol. 2006, 357, 1522-1535.

178. Gruber, C.W.; Cemazar, M.; Clark, R.J.; Horibe, T.; Renda, R.F.; Anderson, M.A.; Craik, D.J. A novel plant protein-disulfide isomerase involved in the oxidative folding of cystine knot defense proteins. J. Biol. Chem. 2007, 282, 20435-20446.

179. Saska, I.; Gillon, A.D.; Hatsugai, N.; Dietzgen, R.G.; Hara-Nishimura, I.; Anderson, M.A.; Craik, D.J. An asparaginyl endopeptidase mediates in vivo protein backbone cyclization. J. Biol. Chem. 2007, 282, 29721-29728.

180. Conlan, B.F.; Gillon, A.D.; Craik, D.J.; Anderson, M.A. Circular proteins and mechanisms of cyclization. Biopolymers 2010, 94, 573-583.

181. Nguyen, G.K.T.; Wang, S.J.; Qiu, Y.B.; Hemu, X.; Lian, Y.L.; Tam, J.P. Butelase 1 is an asx-specific ligase enabling peptide macrocyclization and synthesis. Nat. Chem. Biol. 2014, 10, 732-738.

182. Cao, Y.; Nguyen, G.K.; Tam, J.P.; Liu, C.F. Butelase-mediated synthesis of protein thioesters and its application for tandem chemoenzymatic ligation. Chem. Commun. (Camb) 2015.

183. Chagolla-Lopez, A.; Blanco-Labra, A.; Patthy, A.; Sanchez, R.; Pongor, S. A novel alpha-amylase inhibitor from amaranth (Amaranthus hypocondriacus) seeds. J. Biol. Chem. 1994, 269, 2367523680.

184. Svensson, B.; Fukuda, K.; Nielsen, P.K.; Bonsager, B.C. Proteinaceous alpha-amylase inhibitors. Biochim. Biophys. Acta 2004, 1696, 145-156.

185. Martins, J.C.; Enassar, M.; Willem, R.; Wieruzeski, J.M.; Lippens, G.; Wodak, S.J. Solution structure of the main alpha-amylase inhibitor from amaranth seeds. Eur. J. Biochem. 2001, 268, 2379-2389.

186. Nguyen, P.Q.T.; Wang, S.J.; Kumar, A.; Yap, L.J.; Luu, T.T.; Lescar, J.; Tam, J.P. Discovery and characterization of pseudocyclic cystine-knot alpha-amylase inhibitors with high resistance to heat and proteolytic degradation. FEBS J. 2014, 281, 4351-4366.

187. Nguyen, P.Q.; Luu, T.T.; Bai, Y.; Nguyen, G.K.; Pervushin, K.; Tam, J.P. Allotides: Proline-rich cystine knot alpha-amylase inhibitors from allamanda cathartica. J. Nat. Prod. 2015, 78, 695-704. 
188. Le-Nguyen, D.; Heitz, A.; Chiche, L.; el Hajji, M.; Castro, B. Characterization and 2d nmr study of the stable [9-21, 15-27] 2 disulfide intermediate in the folding of the 3 disulfide trypsin inhibitor eeti ii. Protein Sci. 1993, 2, 165-174.

189. Heitz, A.; Le-Nguyen, D.; Chiche, L. Min-21 and min-23, the smallest peptides that fold like a cystine-stabilized beta-sheet motif: Design, solution structure, and thermal stability. Biochemistry 1999, 38, 10615-10625.

190. Kolmar, H. Biological diversity and therapeutic potential of natural and engineered cystine knot miniproteins. Curr. Opin. Pharmacol. 2009, 9, 608-614.

191. Colgrave, M.L.; Craik, D.J. Thermal, chemical, and enzymatic stability of the cyclotide kalata b1: The importance of the cyclic cystine knot. Biochemistry 2004, 43, 5965-5975.

192. Heitz, A.; Avrutina, O.; Le-Nguyen, D.; Diederichsen, U.; Hernandez, J.F.; Gracy, J.; Kolmar, H.; Chiche, L. Knottin cyclization: Impact on structure and dynamics. BMC Struct. Biol. 2008, 8, 54.

193. Ireland, D.C.; Colgrave, M.L.; Craik, D.J. A novel suite of cyclotides from viola odorata: Sequence variation and the implications for structure, function and stability. Biochem. J. 2006, $400,1-12$.

194. Werle, M.; Kafedjiiski, K.; Kolmar, H.; Bernkop-Schnurch, A. Evaluation and improvement of the properties of the novel cystine-knot microprotein mcoeeti for oral administration. Int. J. Pharm. 2007, 332, 72-79.

195. Werle, M.; Schmitz, T.; Huang, H.L.; Wentzel, A.; Kolmar, H.; Bernkop-Schnurch, A. The potential of cystine-knot microproteins as novel pharmacophoric scaffolds in oral peptide drug delivery. J. Drug Target. 2006, 14, 137-146.

196. Gao, G.H.; Liu, W.; Dai, J.X.; Wang, J.F.; Hu, Z.; Zhang, Y.; Wang, D.C. Solution structure of pafp-s: A new knottin-type antifungal peptide from the seeds of phytolacca americana. Biochemistry 2001, 40, 10973-10978.

197. Cammue, B.P.A.; Debolle, M.F.C.; Terras, F.R.G.; Proost, P.; Vandamme, J.; Rees, S.B.; Vanderleyden, J.; Broekaert, W.F. Isolation and characterization of a novel class of plant antimicrobial peptides from mirabilis-jalapa 1 seeds. J. Biol. Chem. 1992, 267, 2228-2233.

198. Hwang, J.S.; Lee, J.; Hwang, B.; Nam, S.H.; Yun, E.Y.; Kim, S.R.; Lee, D.G. Isolation and characterization of psacotheasin, a novel knottin-type antimicrobial peptide, from psacothea hilaris. J. Microbiol. Biotechnol. 2010, 20, 708-711.

199. Konarev, A.V.; Anisimova, I.N.; Gavrilova, V.A.; Vachrusheva, T.E.; Konechnaya, G.Y.; Lewis, M.; Shewry, P.R. Serine proteinase inhibitors in the compositae: Distribution, polymorphism and properties. Phytochemistry 2002, 59, 279-291.

200. Bode, W.; Greyling, H.J.; Huber, R.; Otlewski, J.; Wilusz, T. The refined 2.0 a x-ray crystal structure of the complex formed between bovine beta-trypsin and cmti-i, a trypsin inhibitor from squash seeds (Cucurbita maxima). Topological similarity of the squash seed inhibitors with the carboxypeptidase a inhibitor from potatoes. FEBS Lett. 1989, 242, 285-292.

201. Polanowski, A.; Wilusz, T.; Nienartowicz, B.; Cieslar, E.; Slominska, A.; Nowak, K. Isolation and partial amino acid sequence of the trypsin inhibitor from the seeds of cucurbita maxima. Acta Biochim. Pol. 1980, 27, 371-382.

202. Korsinczky, M.L.; Schirra, H.J.; Craik, D.J. Sunflower trypsin inhibitor-1. Curr. Protein Pept. Sci. 2004, 5, 351-364. 
203. Hass, G.M.; Ryan, C.A. Carboxypeptidase inhibitor from ripened tomatoes - purification and properties. Phytochemistry 1980, 19, 1329-1333.

204. Arolas, J.L.; Lorenzo, J.; Rovira, A.; Vendrell, J.; Aviles, F.X.; Ventura, S. Secondary binding site of the potato carboxypeptidase inhibitor. Contribution to its structure, folding, and biological properties. Biochemistry 2004, 43, 7973-7982.

205. Marino-Buslje, C.; Venhudova, G.; Molina, M.A.; Oliva, B.; Jorba, X.; Canals, F.; Aviles, F.X.; Querol, E. Contribution of c-tail residues of potato carboxypeptidase inhibitor to the binding to carboxypeptidase a mutagenesis analysis. Eur. J. Biochem. 2000, 267, 1502-1509.

206. Craik, D.J. Plant cyclotides: Circular, knotted peptide toxins. Toxicon 2001, 39, 1809-1813.

207. Gould, A.; Ji, Y.; Aboye, T.L.; Camarero, J.A. Cyclotides, a novel ultrastable polypeptide scaffold for drug discovery. Curr. Pharm. Des. 2011, 17, 4294-4307.

208. Daly, N.L.; Rosengren, K.J.; Craik, D.J. Discovery, structure and biological activities of cyclotides. Adv. Drug Deliv. Rev. 2009, 61, 918-930.

209. Gran, L. On the effect of a polypeptide isolated from "kalata-kalata" (oldenlandia affinis dc) on the oestrogen dominated uterus. Acta Pharmacol. Toxicol. (Copenh) 1973, 33, 400-408.

210. Rosengren, K.J.; Daly, N.L.; Plan, M.R.; Waine, C.; Craik, D.J. Twists, knots, and rings in proteins. Structural definition of the cyclotide framework. J. Biol. Chem. 2003, 278, 8606-8616.

211. Tam, J.P.; Lu, Y.A.; Yang, J.L.; Chiu, K.W. An unusual structural motif of antimicrobial peptides containing end-to-end macrocycle and cystine-knot disulfides. Proc. Natl. Acad. Sci. USA 1999, 96, 8913-8918.

212. Gran, L.; Sletten, K.; Skjeldal, L. Cyclic peptides from oldenlandia affinis dc. Molecular and biological properties. Chem. Biodivers. 2008, 5, 2014-2022.

213. Pranting, M.; Loov, C.; Burman, R.; Goransson, U.; Andersson, D.I. The cyclotide cycloviolacin $\mathrm{o} 2$ from viola odorata has potent bactericidal activity against gram-negative bacteria. J. Antimicrob. Chemother. 2010, 65, 1964-1971.

214. Wong, C.T.; Taichi, M.; Nishio, H.; Nishiuchi, Y.; Tam, J.P. Optimal oxidative folding of the novel antimicrobial cyclotide from hedyotis biflora requires high alcohol concentrations. Biochemistry 2011, 50, 7275-7283.

215. Hernandez, J.F.; Gagnon, J.; Chiche, L.; Nguyen, T.M.; Andrieu, J.P.; Heitz, A.; Trinh Hong, T.; Pham, T.T.; Le Nguyen, D. Squash trypsin inhibitors from momordica cochinchinensis exhibit an atypical macrocyclic structure. Biochemistry 2000, 39, 5722-5730.

216. Chiche, L.; Heitz, A.; Gelly, J.C.; Gracy, J.; Chau, P.T.; Ha, P.T.; Hernandez, J.F.; Le-Nguyen, D. Squash inhibitors: From structural motifs to macrocyclic knottins. Curr. Protein Pept. Sci. 2004, 5 , 341-349.

217. Heitz, A.; Hernandez, J.F.; Gagnon, J.; Hong, T.T.; Pham, T.T.; Nguyen, T.M.; Le-Nguyen, D.; Chiche, L. Solution structure of the squash trypsin inhibitor mcoti-ii. A new family for cyclic knottins. Biochemistry 2001, 40, 7973-7983.

218. Henriques, S.T.; Craik, D.J. Cyclotides as templates in drug design. Drug Discov. Today 2010, 15, 57-64.

219. Shenkarev, Z.O.; Nadezhdin, K.D.; Sobol, V.A.; Sobol, A.G.; Skjeldal, L.; Arseniev, A.S. Conformation and mode of membrane interaction in cyclotides. Spatial structure of kalata b1 bound to a dodecylphosphocholine micelle. FEBS J. 2006, 273, 2658-2672. 
220. Wang, C.K.; Colgrave, M.L.; Ireland, D.C.; Kaas, Q.; Craik, D.J. Despite a conserved cystine knot motif, different cyclotides have different membrane binding modes. Biophys. J. 2009, 97, 1471-1481.

221. Wong, C.T.T.; Rowlands, D.K.; Wong, C.-H.; Lo, T.W.C.; Nguyen, G.K.T.; Li, H.-Y.; Tam, J.P. Orally active peptidic bradykinin b1 receptor antagonists engineered from a cyclotide scaffold for inflammatory pain treatment. Angew. Chem. Int. Ed. 2012, 51, 5620-5624.

222. Hemu, X.; Taichi, M.; Qiu, Y.; Liu, D.-X.; Tam, J.P. Biomimetic synthesis of cyclic peptides using novel thioester surrogates. Pept. Sci. 2013, 100, 492-501.

223. Qiu, Y.; Hemu, X.; Liu, D.X.; Tam, J.P. Selective bi-directional amide bond cleavage of N-methylcysteinyl peptide. Eur. J. Org. Chem. 2014, 2014, 4370-4380, doi: 10.1002/ejoc.201402261.

224. Taichi, M.; Hemu, X.; Qiu, Y.; Tam, J.P. A thioethylalkylamido (tea) thioester surrogate in the synthesis of a cyclic peptide via a tandem acyl shift. Org. Lett. 2013, 15, 2620-2623.

225. Tam, J.P.; Lu, Y.A. Synthesis of large cyclic cystine-knot peptide by orthogonal coupling strategy using unprotected peptide precursor. Tetrahedron Lett. 1997, 38, 5599-5602.

226. Tam, J.P.; Lu, Y.A. A biomimetic strategy in the synthesis and fragmentation of cyclic protein. Protein Sci. 1998, 7, 1583-1592.

227. Daly, N.L.; Love, S.; Alewood, P.F.; Craik, D.J. Chemical synthesis and folding pathways of large cyclic polypeptide: Studies of the cystine knot polypeptide kalata b1. Biochemistry 1999, 38, 10606-10614.

228. Thongyoo, P.; Roque-Rosell, N.; Leatherbarrow, R.J.; Tate, E.W. Chemical and biomimetic total syntheses of natural and engineered mcoti cyclotides. Org. Biomol. Chem. 2008, 6, 1462-1470.

229. Thongyoo, P.; Jaulent, A.M.; Tate, E.W.; Leatherbarrow, R.J. Immobilized protease-assisted synthesis of engineered cysteine-knot microproteins. ChemBioChem 2007, 8, 1107-1109.

230. Kimura, R.H.; Tran, A.T.; Camarero, J.A. Biosynthesis of the cyclotide kalata b1 by using protein splicing. Angew. Chem. Int. Ed. 2006, 45, 973-976.

231. Austin, J.; Wang, W.; Puttamadappa, S.; Shekhtman, A.; Camarero, J.A. Biosynthesis and biological screening of a genetically encoded library based on the cyclotide mcoti-i. ChemBioChem 2009, 10, 2663-2670.

232. Tam, J.P.; Lu, Y.A.; Yu, Q.T. Thia zip reaction for synthesis of large cyclic peptides: Mechanisms and applications. J. Am. Chem. Soc. 1999, 121, 4316-4324.

233. Duvick, J.P.; Rood, T.; Rao, A.G.; Marshak, D.R. Purification and characterization of a novel antimicrobial peptide from maize (Zea mays L.) kernels. J. Biol. Chem. 1992, 267, 18814-18820.

234. Marcus, J.P.; Green, J.L.; Goulter, K.C.; Manners, J.M. A family of antimicrobial peptides is produced by processing of a $7 \mathrm{~s}$ globulin protein in macadamia integrifolia kernels. Plant J. 1999, 19, 699-710.

235. Nolde, S.B.; Vassilevski, A.A.; Rogozhin, E.A.; Barinov, N.A.; Balashova, T.A.; Samsonova, O.V.; Baranov, Y.V.; Feofanov, A.V.; Egorov, T.A.; Arseniev, A.S.; et al. Disulfide-stabilized helical hairpin structure and activity of a novel antifungal peptide ecamp1 from seeds of barnyard grass (Echinochloa crus-galli). J. Biol. Chem. 2011, 286, 25145-25153. 
236. Utkina, L.L.; Andreev, Y.A.; Rogozhin, E.A.; Korostyleva, T.V.; Slavokhotova, A.A.; Oparin, P.B.; Vassilevski, A.A.; Grishin, E.V.; Egorov, T.A.; Odintsova, T.I. Genes encoding 4-cys antimicrobial peptides in wheat triticum kiharae dorof. Et migush.: Multimodular structural organization, instraspecific variability, distribution and role in defence. FEBS J. 2013, 280, 3594-3608.

237. Slavokhotova, A.A.; Rogozhin, E.A.; Musolyamov, A.K.; Andreev, Y.A.; Oparin, P.B.; Berkut, A.A.; Vassilevski, A.A.; Egorov, T.A.; Grishin, E.V.; Odintsova, T.I. Novel antifungal alpha-hairpinin peptide from stellaria media seeds: Structure, biosynthesis, gene structure and evolution. Plant. Mol. Biol. 2014.

238. Conners, R.; Konarev, A.V.; Forsyth, J.; Lovegrove, A.; Marsh, J.; Joseph-Horne, T.; Shewry, P.; Brady, R.L. An unusual helix-turn-helix protease inhibitory motif in a novel trypsin inhibitor from seeds of veronica (veronica hederifolia 1.). J. Biol. Chem. 2007, 282, 27760-27768.

239. Oparin, P.B.; Mineev, K.S.; Dunaevsky, Y.E.; Arseniev, A.S.; Belozersky, M.A.; Grishin, E.V.; Egorov, T.A.; Vassilevski, A.A. Buckwheat trypsin inhibitor with helical hairpin structure belongs to a new family of plant defence peptides. Biochem. J. 2012, 446, 69-77.

240. Ng, Y.M.; Yang, Y.; Sze, K.H.; Zhang, X.; Zheng, Y.T.; Shaw, P.C. Structural characterization and anti-hiv-1 activities of arginine/glutamate-rich polypeptide luffin $\mathrm{p} 1$ from the seeds of sponge gourd (Luffa cylindrica). J. Struct. Biol. 2011, 174, 164-172.

241. Kader, J.C. Lipid-transfer proteins in plants. Annu Rev. Plant. Physiol Plant. Mol. Biol 1996, 47, $627-654$.

242. Carvalho Ade, O.; Gomes, V.M. Role of plant lipid transfer proteins in plant cell physiology-a concise review. Peptides 2007, 28, 1144-1153.

243. Terras, F.R.G.; Goderis, I.J.; Vanleuven, F.; Vanderleyden, J.; Cammue, B.P.A.; Broekaert, W.F. Invitro antifungal activity of a radish (Raphanus-sativus L.) seed protein homologous to nonspecific lipid transfer proteins. Plant. Physiol. 1992, 100, 1055-1058.

244. Molina, A.; Segura, A.; Garcia-Olmedo, F. Lipid transfer proteins (nsltps) from barley and maize leaves are potent inhibitors of bacterial and fungal plant pathogens. FEBS Lett. 1993, 316, $119-122$.

245. Segura, A.; Moreno, M.; Garcia-Olmedo, F. Purification and antipathogenic activity of lipid transfer proteins (ltps) from the leaves of arabidopsis and spinach. FEBS Lett. 1993, 332, 243-246.

246. Cammue, B.P.; Thevissen, K.; Hendriks, M.; Eggermont, K.; Goderis, I.J.; Proost, P.; Van Damme, J.; Osborn, R.W.; Guerbette, F.; Kader, J.C.; et al. A potent antimicrobial protein from onion seeds showing sequence homology to plant lipid transfer proteins. Plant Physiol. 1995, 109, $445-455$.

247. Arondel, V.V.; Vergnolle, C.; Cantrel, C.; Kader, J. Lipid transfer proteins are encoded by a small multigene family in arabidopsis thaliana. Plant Sci. 2000, 157, 1-12.

248. Douliez, J.P.; Pato, C.; Rabesona, H.; Molle, D.; Marion, D. Disulfide bond assignment, lipid transfer activity and secondary structure of a 7-kda plant lipid transfer protein, ltp2. Eur. J. Biochem. 2001, 268, 1400-1403.

249. Pons, J.L.; de Lamotte, F.; Gautier, M.F.; Delsuc, M.A. Refined solution structure of a liganded type 2 wheat nonspecific lipid transfer protein. J. Biol. Chem. 2003, 278, 14249-14256. 
250. Samuel, D.; Liu, Y.J.; Cheng, C.S.; Lyu, P.C. Solution structure of plant nonspecific lipid transfer protein-2 from rice (Oryza sativa). J. Biol. Chem. 2002, 277, 35267-35273.

251. Gomar, J.; Sodano, P.; Sy, D.; Shin, D.H.; Lee, J.Y.; Suh, S.W.; Marion, D.; Vovelle, F.; Ptak, M. Comparison of solution and crystal structures of maize nonspecific lipid transfer protein: A model for a potential in vivo lipid carrier protein. Proteins 1998, 31, 160-171.

252. Tassin, S.; Broekaert, W.F.; Marion, D.; Acland, D.P.; Ptak, M.; Vovelle, F.; Sodano, P. Solution structure of ace-amp1, a potent antimicrobial protein extracted from onion seeds. Structural analogies with plant nonspecific lipid transfer proteins. Biochemistry 1998, 37, 3623-3637.

253. Lee, J.Y.; Min, K.; Cha, H.; Shin, D.H.; Hwang, K.Y.; Suh, S.W. Rice non-specific lipid transfer protein: The 1.6 a crystal structure in the unliganded state reveals a small hydrophobic cavity. J. Mol. Biol. 1998, 276, 437-448.

254. Han, G.W.; Lee, J.Y.; Song, H.K.; Chang, C.; Min, K.; Moon, J.; Shin, D.H.; Kopka, M.L.; Sawaya, M.R.; Yuan, H.S.; et al. Structural basis of non-specific lipid binding in maize lipid-transfer protein complexes revealed by high-resolution x-ray crystallography. J. Mol. Biol. 2001, 308, 263-278.

255. Cheng, H.C.; Cheng, P.T.; Peng, P.; Lyu, P.C.; Sun, Y.J. Lipid binding in rice nonspecific lipid transfer protein-1 complexes from Oryza sativa. Protein Sci. 2004, 13, 2304-2315.

256. Poznanski, J.; Sodano, P.; Suh, S.W.; Lee, J.Y.; Ptak, M.; Vovelle, F. Solution structure of a lipid transfer protein extracted from rice seeds. Comparison with homologous proteins. Eur. J. Biochem. 1999, 259, 692-708.

257. Gincel, E.; Simorre, J.P.; Caille, A.; Marion, D.; Ptak, M.; Vovelle, F. Three-dimensional structure in solution of a wheat lipid-transfer protein from multidimensional 1h-nmr data. A new folding for lipid carriers. Eur. J. Biochem. 1994, 226, 413-422.

258. Charvolin, D.; Douliez, J.P.; Marion, D.; Cohen-Addad, C.; Pebay-Peyroula, E. The crystal structure of a wheat nonspecific lipid transfer protein (ns-ltp1) complexed with two molecules of phospholipid at 2.1 a resolution. Eur. J. Biochem. 1999, 264, 562-568.

259. Lerche, M.H.; Kragelund, B.B.; Bech, L.M.; Poulsen, F.M. Barley lipid-transfer protein complexed with palmitoyl coa: The structure reveals a hydrophobic binding site that can expand to fit both large and small lipid-like ligands. Structure 1997, 5, 291-306.

260. Lerche, M.H.; Poulsen, F.M. Solution structure of barley lipid transfer protein complexed with palmitate. Two different binding modes of palmitate in the homologous maize and barley nonspecific lipid transfer proteins. Protein Sci. 1998, 7, 2490-2498.

261. Gomar, J.; Petit, M.C.; Sodano, P.; Sy, D.; Marion, D.; Kader, J.C.; Vovelle, F.; Ptak, M. Solution structure and lipid binding of a nonspecific lipid transfer protein extracted from maize seeds. Protein Sci. 1996, 5, 565-577.

262. Castro, M.S.; Gerhardt, I.R.; Orru, S.; Pucci, P.; Bloch, C., Jr. Purification and characterization of a small $(7.3 \mathrm{kda})$ putative lipid transfer protein from maize seeds. J. Chromatogr. B Analyt. Technol. Biomed. Life Sci. 2003, 794, 109-114.

263. Gizatullina, A.K.; Finkina, E.I.; Mineev, K.S.; Melnikova, D.N.; Bogdanov, I.V.; Telezhinskaya, I.N.; Balandin, S.V.; Shenkarev, Z.O.; Arseniev, A.S.; Ovchinnikova, T.V. Recombinant production and solution structure of lipid transfer protein from lentil lens culinaris. Biochem. Biophys. Res. Commun. 2013, 439, 427-432. 
264. Lin, K.F.; Liu, Y.N.; Hsu, S.T.; Samuel, D.; Cheng, C.S.; Bonvin, A.M.; Lyu, P.C. Characterization and structural analyses of nonspecific lipid transfer protein 1 from mung bean. Biochemistry 2005, 44, 5703-5712.

265. Da Silva, P.; Landon, C.; Industri, B.; Marais, A.; Marion, D.; Ponchet, M.; Vovelle, F. Solution structure of a tobacco lipid transfer protein exhibiting new biophysical and biological features. Proteins 2005, 59, 356-367.

266. Cheng, C.S.; Chen, M.N.; Lai, Y.T.; Chen, T.; Lin, K.F.; Liu, Y.J.; Lyu, P.C. Mutagenesis study of rice nonspecific lipid transfer protein 2 reveals residues that contribute to structure and ligand binding. Proteins 2008, 70, 695-706.

267. Cheng, C.S.; Samuel, D.; Liu, Y.J.; Shyu, J.C.; Lai, S.M.; Lin, K.F.; Lyu, P.C. Binding mechanism of nonspecific lipid transfer proteins and their role in plant defense. Biochemistry 2004, 43, 13628-13636.

268. Lin, P.; Xia, L.; Wong, J.H.; Ng, T.B.; Ye, X.; Wang, S.; Shi, X. Lipid transfer proteins from brassica campestris and mung bean surpass mung bean chitinase in exploitability. J. Pept. Sci. 2007, 13, 642-648.

269. Molina, A.; Garcia-Olmedo, F. Enhanced tolerance to bacterial pathogens caused by the transgenic expression of barley lipid transfer protein ltp2. Plant J. 1997, 12, 669-675.

270. Lascombe, M.B.; Bakan, B.; Buhot, N.; Marion, D.; Blein, J.P.; Larue, V.; Lamb, C.; Prange, T. The structure of "defective in induced resistance" protein of arabidopsis thaliana, dir1, reveals a new type of lipid transfer protein. Protein Sci. 2008, 17, 1522-1530.

271. Yeats, T.H.; Rose, J.K. The biochemistry and biology of extracellular plant lipid-transfer proteins (ltps). Protein Sci. 2008, 17, 191-198.

272. Kader, J.C. Proteins and intracellular exchange of lipids .1. Stimulation of phospholipid exchange between mitochondria and microsomal fractions by proteins isolated from potato-tuber. Biochem. Biophys. Acta 1975, 380, 31-44.

273. Kader, J.C.; Julienne, M.; Vergnolle, C. Purification and characterization of a spinach-leaf protein capable of transferring phospholipids from liposomes to mitochondria or chloroplasts. Eur. J. Biochem. 1984, 139, 411-416.

274. Thoma, S.; Kaneko, Y.; Somerville, C. A non-specific lipid transfer protein from arabidopsis is a cell wall protein. Plant J. 1993, 3, 427-436.

275. Pyee, J.; Yu, H.S.; Kolattukudy, P.E. Identification of a lipid transfer protein as the major protein in the surface wax of broccoli (Brassica oleracea) leaves. Archiv. Biochem. Biophys. 1994, 311, $460-468$.

276. Regente, M.C.; Giudici, A.M.; Villalain, J.; de la Canal, L. The cytotoxic properties of a plant lipid transfer protein involve membrane permeabilization of target cells. Lett. Appl. Microbiol. 2005, 40, 183-189.

277. Segura, A.; Moreno, M.; Madueno, F.; Molina, A.; Garcia-Olmedo, F. Snakin-1, a peptide from potato that is active against plant pathogens. Mol. Plant Microbe Interact. 1999, 12, 16-23.

278. Berrocal-Lobo, M.; Segura, A.; Moreno, M.; Lopez, G.; Garcia-Olmedo, F.; Molina, A. Snakin-2, an antimicrobial peptide from potato whose gene is locally induced by wounding and responds to pathogen infection. Plant Physiol. 2002, 128, 951-961. 
279. Porto, W.F.; Franco, O.L. Theoretical structural insights into the snakin/gasa family. Peptides 2013, 44, 163-167.

280. Bindschedler, L.V.; Whitelegge, J.P.; Millar, D.J.; Bolwell, G.P. A two component chitin-binding protein from french bean -- association of a proline-rich protein with a cysteine-rich polypeptide. FEBS Lett. 2006, 580, 1541-1546.

281. Daneshmand, F.; Zare-Zardini, H.; Ebrahimi, L. Investigation of the antimicrobial activities of snakin-z, a new cationic peptide derived from zizyphus jujuba fruits. Nat. Prod. Res. 2013, 27, 2292-2296.

282. Mandal, S.M.; Porto, W.F.; Dey, P.; Maiti, M.K.; Ghosh, A.K.; Franco, O.L. The attack of the phytopathogens and the trumpet solo: Identification of a novel plant antifungal peptide with distinct fold and disulfide bond pattern. Biochimie 2013, 2013, 1939-1948.

283. Tailor, R.H.; Acland, D.P.; Attenborough, S.; Cammue, B.P.; Evans, I.J.; Osborn, R.W.; Ray, J.A.; Rees, S.B.; Broekaert, W.F. A novel family of small cysteine-rich antimicrobial peptides from seed of impatiens balsamina is derived from a single precursor protein. J. Biol. Chem. 1997, 272, 24480-24487.

284. Thevissen, K.; Francois, I.E.; Sijtsma, L.; van Amerongen, A.; Schaaper, W.M.; Meloen, R.; Posthuma-Trumpie, T.; Broekaert, W.F.; Cammue, B.P. Antifungal activity of synthetic peptides derived from impatiens balsamina antimicrobial peptides ib-amp1 and ib-amp4. Peptides 2005, 26, 1113-1119.

285. Patel, S.U.; Osborn, R.; Rees, S.; Thornton, J.M. Structural studies of impatiens balsamina antimicrobial protein (ib-amp1). Biochemistry 1998, 37, 983-990.

286. Wang, P.; Bang, J.K.; Kim, H.J.; Kim, J.K.; Kim, Y.; Shin, S.Y. Antimicrobial specificity and mechanism of action of disulfide-removed linear analogs of the plant-derived cys-rich antimicrobial peptide ib-amp1. Peptides 2009, 30, 2144-2149.

287. Fujimura, M.; Ideguchi, M.; Minami, Y.; Watanabe, K.; Tadera, K. Amino acid sequence and antimicrobial activity of chitin-binding peptides, pp-amp 1 and pp-amp 2, from japanese bamboo shoots (phyllostachys pubescens). Biosci. Biotechnol. Biochem. 2005, 69, 642-645.

288. Astafieva, A.A.; Rogozhin, E.A.; Odintsova, T.I.; Khadeeva, N.V.; Grishin, E.V.; Egorov Ts, A. Discovery of novel antimicrobial peptides with unusual cysteine motifs in dandelion taraxacum officinale wigg. Flowers. Peptides 2012, 36, 266-271.

289. Astafieva, A.A.; Rogozhin, E.A.; Andreev, Y.A.; Odintsova, T.I.; Kozlov, S.A.; Grishin, E.V.; Egorov, T.A. A novel cysteine-rich antifungal peptide toamp4 from taraxacum officinale wigg. Flowers. Plant Physiol. Biochem. 2013, 70, 93-99.

290. McManus, A.M.; Nielsen, K.J.; Marcus, J.P.; Harrison, S.J.; Green, J.L.; Manners, J.M.; Craik, D.J. Miamp1, a novel protein from macadamia integrifolia adopts a greek key beta-barrel fold unique amongst plant antimicrobial proteins. J. Mol. Biol. 1999, 293, 629-638.

291. Silva, O.N.; Porto, W.F.; Migliolo, L.; Mandal, S.M.; Gomes, D.G.; Holanda, H.H.; Silva, R.S.; Dias, S.C.; Costa, M.P.; Costa, C.R.; et al. Cn-amp1: A new promiscuous peptide with potential for microbial infections treatment. Biopolymers 2012, 98, 322-331.

292. Mandal, S.M.; Migliolo, L.; Das, S.; Mandal, M.; Franco, O.L.; Hazra, T.K. Identification and characterization of a bactericidal and proapoptotic peptide from cycas revoluta seeds with DNA binding properties. J. Cell. Biochem. 2012, 113, 184-193. 
293. Pelegrini, P.B.; Murad, A.M.; Silva, L.P.; Dos Santos, R.C.; Costa, F.T.; Tagliari, P.D.; Bloch, C., Jr.; Noronha, E.F.; Miller, R.N.; Franco, O.L. Identification of a novel storage glycine-rich peptide from guava (psidium guajava) seeds with activity against gram-negative bacteria. Peptides $\mathbf{2 0 0 8}$, 29, 1271-1279.

294. Tavares, L.S.; Rettore, J.V.; Freitas, R.M.; Porto, W.F.; Duque, A.P.; Singulani Jde, L.; Silva, O.N.; Detoni Mde, L.; Vasconcelos, E.G.; Dias, S.C.; et al. Antimicrobial activity of recombinant pg-amp1, a glycine-rich peptide from guava seeds. Peptides 2012, 37, 294-300.

295. Park, C.J.; Park, C.B.; Hong, S.S.; Lee, H.S.; Lee, S.Y.; Kim, S.C. Characterization and cdna cloning of two glycine- and histidine-rich antimicrobial peptides from the roots of shepherd's purse, capsella bursa-pastoris. Plant. Mol. Biol. 2000, 44, 187-197.

296. Rahnamaeian, M. Antimicrobial peptides: Modes of mechanism, modulation of defense responses. Plant Signal. Behav. 2011, 6, 1325-1332.

297. Barbosa Pelegrini, P.; Del Sarto, R.P.; Silva, O.N.; Franco, O.L.; Grossi-de-Sa, M.F. Antibacterial peptides from plants: What they are and how they probably work. Biochem. Res. Int. 2011, 2011, 250349.

298. Kagan, B.L.; Selsted, M.E.; Ganz, T.; Lehrer, R.I. Antimicrobial defensin peptides form voltage-dependent ion-permeable channels in planar lipid bilayer membranes. Proc. Natl. Acad. Sci. USA 1990, 87, 210-214.

299. Miyazaki, Y.; Aoki, M.; Yano, Y.; Matsuzaki, K. Interaction of antimicrobial peptide magainin 2 with gangliosides as a target for human cell binding. Biochemistry 2012, 51, 10229-10235.

300. Sarika; Iquebal, M.A.; Rai, A. Biotic stress resistance in agriculture through antimicrobial peptides. Peptides 2012, 36, 322-330.

301. Montesinos, E. Antimicrobial peptides and plant disease control. FEMS Microbiol. Lett. 2007, 270, 1-11.

302. Jagadish, K.; Camarero, J.A. Cyclotides, a promising molecular scaffold for peptide-based therapeutics. Biopolymers 2010, 94, 611-616.

303. Yu, Q.; Lehrer, R.I.; Tam, J.P. Engineered salt-insensitive alpha-defensins with end-to-end circularized structures. J. Biol. Chem. 2000, 275, 3943-3949.

304. Chan, L.Y.; Gunasekera, S.; Henriques, S.T.; Worth, N.F.; Le, S.J.; Clark, R.J.; Campbell, J.H.; Craik, D.J.; Daly, N.L. Engineering pro-angiogenic peptides using stable, disulfide-rich cyclic scaffolds. Blood 2011, 118, 6709-6717.

305. Eliasen, R.; Daly, N.L.; Wulff, B.S.; Andresen, T.L.; Conde-Frieboes, K.W.; Craik, D.J. Design, synthesis, structural and functional characterization of novel melanocortin agonists based on the cyclotide kalata b1. J. Biol. Chem. 2012, 287, 40493-40501.

306. Abdallah, N.A.; Shah, D.; Abbas, D.; Madkour, M. Stable integration and expression of a plant defensin in tomato confers resistance to fusarium wilt. GM Crops 2010, 1, 344-350.

(C) 2015 by the authors; licensee MDPI, Basel, Switzerland. This article is an open access article distributed under the terms and conditions of the Creative Commons Attribution license (http://creativecommons.org/licenses/by/4.0/). 